\title{
Long term detection of water depth changes of coastal wetlands in the Yellow River Delta based on distributed scatterer interferometry
}

\author{
Chou Xie ${ }^{\mathrm{a}}$, Ji Xu ${ }^{\mathrm{b}, *}$, Yun Shao ${ }^{\mathrm{a}}$, Baoshan Cui ${ }^{\mathrm{c}}$, Kanika Goel ${ }^{\mathrm{d}}$, Yunjun Zhang ${ }^{\mathrm{e}}$, Minghuan Yuan ${ }^{\mathrm{f}}$ \\ a Institute of Remote Sensing and Digital Earth, Chinese Academy of Sciences, Beijing 100101, China \\ b Chinese Academy of Surveying and Mapping, Beijing 100039, China \\ c State Key Joint Laboratory of Environmental Simulation and Pollution Control, School of Environment, Beijing Normal University, Beijing 100875, China \\ d Remote Sensing Technology Institute (IMF), German Aerospace Center (DLR), Oberpfaffenhofen, 82234 Wessling, Germany \\ e Department of Marine Geosciences, Rosenstiel School of Marine and Atmospheric School, University of Miami, Miami, FL 33149-1098, United States \\ ${ }^{f}$ College of Resource and Environment, Hunan Normal University, Changsha 410081, China
}

\section{A R T I C L E I N F O}

\section{Article history:}

Received 5 September 2014

Received in revised form 26 March 2015

Accepted 12 April 2015

Available online xxxx

\section{Keywords:}

Wetlands

Water depth

Interferometry

Distributed scatterer

The Yellow River Delta

\begin{abstract}
A B S T R A C T
Coastal wetland ecosystems are among the most productive yet highly threatened systems in the world, and population growth and increasing economic development have resulted to extremely rapid degradation and loss of coastal wetlands. Spaceborne differential Interferometry SAR has proven a remarkable potential in wetland applications, including water level monitoring in high spatial resolution. However, due to the absence of ground observations for calibration and validation, long term monitoring of water depth, which is essential to evaluate ecosystem health of wetlands, is difficult to be estimated from spaceborne InSAR data. We present a new differential synthetic aperture radar method for temporal evolution of water depth in wetlands. The presented technique is based on distributed scatter interferogram technique in order to provide a spatially dense hydrological observation for coastal wetlands, which are characterized by high temporal decorrelation. This method adapts a strategy by forming optimum interferogram network to get a balance between maximum interferometric information preservation and computational cost reduction, and implements spatial adaptive filtering to reduce noise and enhance fringe visibility on distributed scatterers. Refined InSAR observation is tied to absolute reference frame to generate long term high resolution water level time-series using stage data. We transform water level time-series to long term observation of water depth with assistance of a dense measurement network of water depth. We present water depth time-series obtained using the data acquired from 2007 to 2010 by the ALOS satellite, which supplied significant information to evaluate ecological performance of wetland restoration in the Yellow River Delta.
\end{abstract}

C 2015 Elsevier Inc. All rights reserved.

\section{Introduction}

Wetland provides a productive ecosystem and favorable habitat for a wide variety of plant and animal species, and is among the most productive ecological systems in the world (Costanza, Kubiszewski, Roman, \& Sutton, 2011). In recent years, much attention has been directed toward the formulation and operation of sustainable management strategies for wetlands (Turner et al., 2000). Despite the increasing recognition of the need to conserve wetlands, extremely rapid degradation and the loss of wetlands still continued because of population growth and increasing economic development (Millennium Ecosystem Assessment, 2005). A key approach for ensuring the future of wetlands and their services is to maintain the normal processes more or less determined by the interactions among wetland hydrology and geomorphology, saturated soil and vegetation (An et al., 2007).

\footnotetext{
* Corresponding author.
}

Remote sensing approaches reveal a great potential to investigate temporal evolution of vegetation patterns (Taramelli et al., 2010), severe land subsidence (Higgins et al., 2013; Liu \& Huang, 2013; Taramelli et al., 2014), devastating pollution induced by oil industry (Kuenzer, van Beijma, Gessner, \& Dech, 2014b), and upstream water diversion threatening water supply in coastal areas (Bharati, et al., 2008). Existing airborne and spaceborne methods have also been used to measure components of surface water hydraulics to guide water management practices (Alsdorf, Rodriguez, \& Lettenmaier, 2007). Radar altimeters have been accepted as successful tools for measuring the elevation of the ocean surface. However, radar altimeters might not be so hydrologically useful for measuring the elevation of freshwater surface because they always miss too many freshwater bodies due to their orbital spacings (Frappart, Calmant, Cauhopé, Seyler, \& Cazenave, 2006). The airborne LiDAR method could also supply hydrological information with high accuracy (James, Watson, \& Hansen, 2006; Jones, Poole, O'Daniel, Mertes, \& Stanford, 2008), but it is not suitable for large area and long-term development observation as costs of airborne LiDAR mapping increase linearly with 
Table 1

Summary of wetland InSAR applications, including key findings of the respective studies.

\begin{tabular}{|c|c|c|c|c|c|c|c|}
\hline $\mathrm{Nr}$ & Reference & Study area & Center lat/long & Time extend & Data sets & Wetland type & Key findings \\
\hline 1 & $\begin{array}{l}\text { Alsdorf et al. (2000); } \\
\text { Alsdorf et al. (2001) }\end{array}$ & Amazon & $\mathrm{S} 3.5^{\circ} / \mathrm{W} 61.5^{\circ}$ & 1997 & SIR-C and JERS-1 & Floodplain & $\begin{array}{l}\text { Interferometric analysis of L-band SAR imagery can yield centimeter-scale measurements } \\
\text { of water-level changes throughout inundated floodplain vegetation. }\end{array}$ \\
\hline 2 & $\begin{array}{l}\text { Wdowinski, Amelung, } \\
\text { Miralles-Wilhelm, } \\
\text { Dixon, and Carande (2004) }\end{array}$ & Everglades, Florida & $\mathrm{N} 26.3^{\circ} / \mathrm{W} 80.3^{\circ}$ & 1994 & JERS-1 & $\begin{array}{l}\text { Marshes, swamps, } \\
\text { and mangrove }\end{array}$ & $\begin{array}{l}\text { A subset of L-band InSAR observations are capable constraining a flow model and } \\
\text { improve estimation of surface flow parameters. }\end{array}$ \\
\hline 3 & Lu et al. (2005) & Louisiana & $\mathrm{N} 29.8^{\circ} / \mathrm{W} 90.6^{\circ}$ & 1993-1998 & ERS-1/2 & Swamp forest & C-band InSAR images can measure water level change beneath moderately dense tree cover. \\
\hline 4 & Wdowinski et al. (2008) & Everglades, Florida & $\mathrm{N} 26.3^{\circ} / \mathrm{W} 80.3^{\circ}$ & 1993-1996 & JERS-1 & $\begin{array}{l}\text { Marshes, swamps, } \\
\text { and mangrove }\end{array}$ & $\begin{array}{l}\text { In the managed wetlands, fringes are organized, follow patterns related to some of the } \\
\text { managed water control structures and have high fringe-rate. In the natural flow areas, } \\
\text { fringes are irregular and have a low fringe rate. }\end{array}$ \\
\hline 5 & Lu and Kwoun (2008) & Louisiana & $\mathrm{N} 29.8^{\circ} / \mathrm{W} 90.6^{\circ}$ & $\begin{array}{l}1992-1999 \\
2002-2005\end{array}$ & RADARSAT -1 and ERS & Swamp forests & $\begin{array}{l}\text { The water-level changes from C-band InSAR measurements were further quantified using } \\
\text { both vertical-transmit and vertical receive (VV) polarized ERS-1/ERS-2 and horizontal-transmit } \\
\text { and horizontal-receive (HH) polarized Radarsat-1 images. }\end{array}$ \\
\hline 6 & Kim et al. (2009) & Louisiana & $\mathrm{N} 29.8^{\circ} / \mathrm{W} 90.6^{\circ}$ & $2007-2008$ & $\begin{array}{l}\text { PALSAR, RADARSAT- } 1 \\
\text { and ENVISAT altimeter }\end{array}$ & Swamp forests & $\begin{array}{l}\text { InSAR and satellite radar altimetry can be integrated for measuring absolute or geocentric } \\
\text { water level changes. }\end{array}$ \\
\hline 7 & Hong et al. (2010a) & Everglades, Florida & $\mathrm{N} 26.3^{\circ} / \mathrm{W} 80.3^{\circ}$ & 2008 & TerraSAR-X & $\begin{array}{l}\text { Marshes, swamps, } \\
\text { and mangrove }\end{array}$ & $\begin{array}{l}\text { X-band InSAR with a short temporal baseline can detect and monitor surface water-level } \\
\text { changes in wetland with accuracy of } 2-4 \mathrm{~cm} \text {. }\end{array}$ \\
\hline 8 & Hong et al. (2010b) & Everglades, Florida & $\mathrm{N} 26.3^{\circ} / \mathrm{W} 80.3^{\circ}$ & 2006-2007 & RADARSAT- 1 & Marshes & $\begin{array}{l}\text { An InSAR technique called Small Temporal Baseline Subset (STBAS) was presented } \\
\text { for monitoring absolute water level time series with centimeters accuracy using radar } \\
\text { interferograms over wetlands. }\end{array}$ \\
\hline 9 & Gondwe et al. (2010) & Sian Ka'an in Yucatan & $\mathrm{N} 20.0^{\circ} / \mathrm{W} 87.5^{\circ}$ & 2006-2008 & RADARSAT- 1 & $\begin{array}{l}\text { Marshes, swamps, } \\
\text { and mangroves }\end{array}$ & $\begin{array}{l}\text { Analysis of SAR and InSAR data over the Sian Ka'an wetlands showed that these remotely } \\
\text { sensed data can yield local-scale water divides and surface water flow directions } \\
\text { over this vast ground-water-fed wetland. }\end{array}$ \\
\hline 10 & Hong et al. (2010b) & Everglades, Florida & $\mathrm{N} 26.3^{\circ} / \mathrm{W} 80.3^{\circ}$ & 2006-2007 & RADARSAT- 1 & Marshes & $\begin{array}{l}\text { All the quadrant polarimetric C-band interferograms showed very similar fringe patterns } \\
\text { regardless of the polarization type, suggesting that water level changes } \\
\text { can be detected in all polarizations. }\end{array}$ \\
\hline 11 & Poncos et al. (2013) & the Danube Delta & $\mathrm{N} 45.0^{\circ} / \mathrm{E} 29.5^{\circ}$ & $2007-2010$ & ALOS PALSAR & Marshes & $\begin{array}{l}\text { DInSAR measurements were compared with extrapolated water level change values obtained } \\
\text { from an existing mathematical model of the hydrological regime in the Danube Delta. }\end{array}$ \\
\hline 12 & Xie et al. (2013) & the Yellow River Delta & $\mathrm{N} 37.7^{\circ} / \mathrm{E} 119.0^{\circ}$ & 2008-2009 & ALOS PALSAR & Marshes & $\begin{array}{l}\text { HH polarization L-band synthetic aperture radar data could detect water level changes with } \\
\text { centimeters accuracy in reed meshes. }\end{array}$ \\
\hline 13 & Kim et al. (2013) & Everglades, Florida & $\mathrm{N} 26.3^{\circ} / \mathrm{W} 80.3^{\circ}$ & $\begin{array}{l}1993-1999 \\
2004-2005\end{array}$ & $\begin{array}{l}\text { JERS-1, ERS- } 1 / 2 \text {, ENVISAT, } \\
\text { and RADARSAT-1 }\end{array}$ & $\begin{array}{l}\text { Marshes, swamps, } \\
\text { and mangrove }\end{array}$ & $\begin{array}{l}\text { The relation between interferometric coherence in the Everglades wetland, inherent } \\
\text { SAR parameters of polarization, incidence angle, and wavelength, wetland types, and } \\
\text { physical and temporal InSAR components was analyzed. }\end{array}$ \\
\hline 14 & Kim et al. (2014) & Everglades, Florida & $\mathrm{N} 26.3^{\circ} / \mathrm{W} 80.3^{\circ}$ & 2007-2011 & PALSAR and RADARSAT- 1 & $\begin{array}{l}\text { Marshes, swamps, } \\
\text { and mangrove }\end{array}$ & $\begin{array}{l}\text { The complementarity of SAR backscatter coefficient differencing and interferometry (InSAR) } \\
\text { can improve estimation of high spatial resolution water level variations in the Everglades. }\end{array}$ \\
\hline 15 & Hong and Wdowinski (2014) & Everglades, Florida & $\mathrm{N} 26.3^{\circ} / \mathrm{W} 80.3^{\circ}$ & 2007-2011s & ALOS PALSAR & Marshes & $\begin{array}{l}\text { A new multitrack multitemporal algorithm was presented to calculate absolute water level } \\
\text { time series with improved frequency of acquisitions and very high spatial resolution }(40 \mathrm{~m}) \text {. } \\
\text { The main contribution of the multitrack algorithm is the improved time span between } \\
\text { acquisitions, from } 46 \text { days in the single-track algorithm down to } 7 \text { days in the multitrack algorithm. }\end{array}$ \\
\hline
\end{tabular}


mapped area and revisit frequency. The problem for wetland application of spaceborne LiDAR, such as the Geoscience Laser Altimeter System (GLAS) instrument onboard ICESat (Schutz, Zwally, Shuman, Hancock, \& DiMarzio, 2005), is the removal of the bank or vegetation contamination for the smaller water bodies and the identification of water and land returns (Alsdorf et al., 2007).

SAR backscattering coefficient in wetland studies has been very useful for characterizing wetland types (Bartsch, Kidd, Pathe, Scipal, \& Wagner, 2007; Patel, Hari, \& Ranganath, 2009), delineating inundated surface area (Bourgeau-Chavez et al., 2005), and monitoring flood dynamics (Alsdorf \& Rodriguez, 2005; Bartsch et al., 2006; Kuenzer et al., 2013). Spaceborne differential Interferometry SAR has proven a remarkable potential in water level monitoring with high spatial resolution over wide areas (Table 1), and was successfully utilized to study hydrodynamics in the Everglades (Hong, Wdowinski, \& Kim, 2010a; Hong, Wdowinski, Kim, \& Won, 2010b; Kim, Wdowinski, Amelung, Dixon, \& Won, 2013; Kim et al., 2014; Wdowinski et al., 2004, 2008), Louisiana (Kim et al., 2009; Lu \& Kwoun, 2008; Lu et al., 2005), the Yellow River Delta (Xie, Shao, Xu, Wan, \& Fang, 2013), the Sian Ka'an in Yucatan (Gondwe, Hong, Wdowinski, \& Bauer-Gottwein, 2010), and the Danube Delta (Poncos, Teleaga, Bondar, \& Oaie, 2013). All of these studies rely on the fact that the water beneath flooded vegetation can provide double-bounce backscattering (Kasischke et al., 2003; Kiage, Walker, Balasubramanian, Babin, \& Barras, 2005; Wang, Hess, Filoso, \& Melack, 1995), which allows InSAR coherence to be maintained. HH polarized L-band SAR data with relatively small incidence angle are most favorable for detection water level changes in wetlands (Alsdorf et al., 2000; Wdowinski et al., 2008; Xie et al., 2013). The coherence level of L-band data depends mainly on perpendicular baseline, while the coherence level of C-band data is strongly dependent on temporal baseline (Kim et al., 2013). Polarization is also crucial wetland applications, with $\mathrm{HH}$ polarization being more coherent than VV polarization over swamp forest (Hong et al., 2010b; Lu \& Kwoun, 2008; Lu et al., 2005). Kim et al. (2014) studied further the correlation between SAR backscatter and wetland water level changes, and tested the possibility of estimating the water level changes from SAR backscatter. Meanwhile, satellite radar altimetry can be utilized as a powerful complementary of InSAR to estimate absolute water level changes in the swamp forests (Alsdorf, Smith, \& Melack, 2001; Kim et al., 2009).

Long term hydrological monitoring is essential to evaluate the health performance of a wetland ecosystem. Persistent Scatter Interferometry (PSI) and Small Baseline Subsets (SBAS) techniques, which monitor displacement time series using successive InSAR observations, have led to a significant progress in InSAR technology (Berardino, Fornaro, Lanari, \& Sansosti, 2002; Ferretti, Prati, \& Rocca, $1999,2001)$. However, due to the low coherence of natural targets in coastal wetland, most previous InSAR works seldom use PSI and related techniques to monitor multi-temporal hydrological changes. The one exception is the study of Hong et al. (2010b) and Hong \& Wdowinski, (2014), who built upon the STBAS methodology to retrieve the absolute water level time series, but only using InSAR observations with very small temporal baselines. In recent years, a new approach called Distributed Scatter Interferometry (DSI) has been proposed to retrieve displacement time-series from natural targets (Ferretti et al., 2011; Goel \& Adam, 2012). DSI technique promises long term high quality interferometric fringe map over wetlands.

In this study we adopt the DSI technique to obtain long term water level from successive L-band InSAR observations over wetlands. Meanwhile, we make a step forward from absolute water level to water depth time series with the assistance of dense water depth measurement network. The paper is organized as follows. Section 2 and Section 3 describe coastal wetlands in the Yellow River Delta and collected SAR data and stage data respectively; Section 4 explains the distributed scatterer interferometry technique and the method adopted to transfer water level to water depth;
Section 5 is dedicated to the presentation of the obtained results. Discussion and further developments are addressed in Section 6 and Section 7 , respectively.

\section{Study area}

We concentrate our study on a site located in the Yellow River Delta, where one of the most typical river delta wetlands in warm temperate climates is located. The Yellow River Delta has a monsoon-influenced, four-season climate that lies in transition between the humid continental and humid subtropical regimes (Xue, 1993; Yue, Liu, Jørgensen, \& Ye, 2003). Topography is nearly flat with a maximum elevation change of $10 \mathrm{~m}$.

A great amount of sand and soil, which is carried by the river from upstream and deposited in the delta, leads to special wetland landscape (Li, Wang, Deng, Hu, \& Hu, 2009). The area of intermittently inundated wetlands (such as reed marshes, bottomland forests, agricultural fields and saline marshes) accounts for $37 \%$ of the total area. These coastal wetlands can be thought of as "biological supermarkets" because they provide a source of substantial biodiversity in supporting numerous plant and animal species (Mitsch, 1995). The degradation and loss of coastal wetlands and species in the area have been driven by infrastructure development (such as dams, dikes and levees), land conversion, water withdrawals, land subsidence due to petroleum extraction and pollution (Kuenzer et al., 2014a). A wetland recovery project, which aims to restore and enhance wetland benefits by re-establishing natural ecological processes, was implemented to restore reed marshes in the Yellow River Delta from July 2002 (Cui, Tang, Zhao, \& Bai, 2009a; Cui, Yang, Yang, \& Zhang, 2009b; Cui, Zhao, Yang, Tang, \& Tan, 2006).

The study area consists of primarily three different land cover types: bottomland forest, agricultural fields and reed marsh. Bottomland forest (BF) and agricultural field (AF) covers are found to the north of the study area, and agricultural field accounts for more than $60 \%$ of this area. Agricultural field shows higher backscatter coefficients than other land covers. Reed marshes are separated into two isolated parts (RM1 and RM2) by levees, which prevent flow between each other. The total area of RM1 and RM2 is $9 \mathrm{~km}^{2}$ and $4 \mathrm{~km}^{2}$ respectively. As managed wetlands surrounded by barriers such as levees, RM1 and RM2 do not have great spatial variations of water level at most of the times. Most parts of RM1 are dry during most of the year, and are bright as seen in the backscatter intensity image in the February scene (red band in Fig. 1(c)) and in August (blue band in Fig. 1(c). There are clear irregular boundaries between the dry part and the inundated part on RM1, and the irregular boundaries can be easily recognized in Fig. 1(c). RM2 is connected with the Yellow River by the channel (the red line parallel to the southwest boundary of the study area in Fig. 1(c), and sufficient water supply leads to large areas of surface water in the area. Owing to variation in water level and biomass density (see Fig. 2), some sites of inundated reed marsh were bright from backscattering intensity in the February scene, and some sites were bright in May (green band in Fig. 1(c)). Due to flow management system via the channel connected to the Yellow River, the typical managed flow is from stage gate on the channel to reed marsh. Such flow occurs during the end of June every year, when water level in the Yellow River is high. Natural flow pattern in RM2 is from north to south during the majority of the days.

\section{Materials and pre-processing}

\subsection{SAR data}

We acquired 17 images of the Phased Array type L-band Synthetic Aperture Radar (PALSAR) data from the Advanced Land Observing Satellite (ALOS) to generate InSAR maps. The vertical blue lines in Fig. 3 mark the ALOS PALSAR acquisition dates. The obtained PALSAR data are from Fine Beam mode, offering a resolution of $30 \mathrm{~m}$ on ground. 


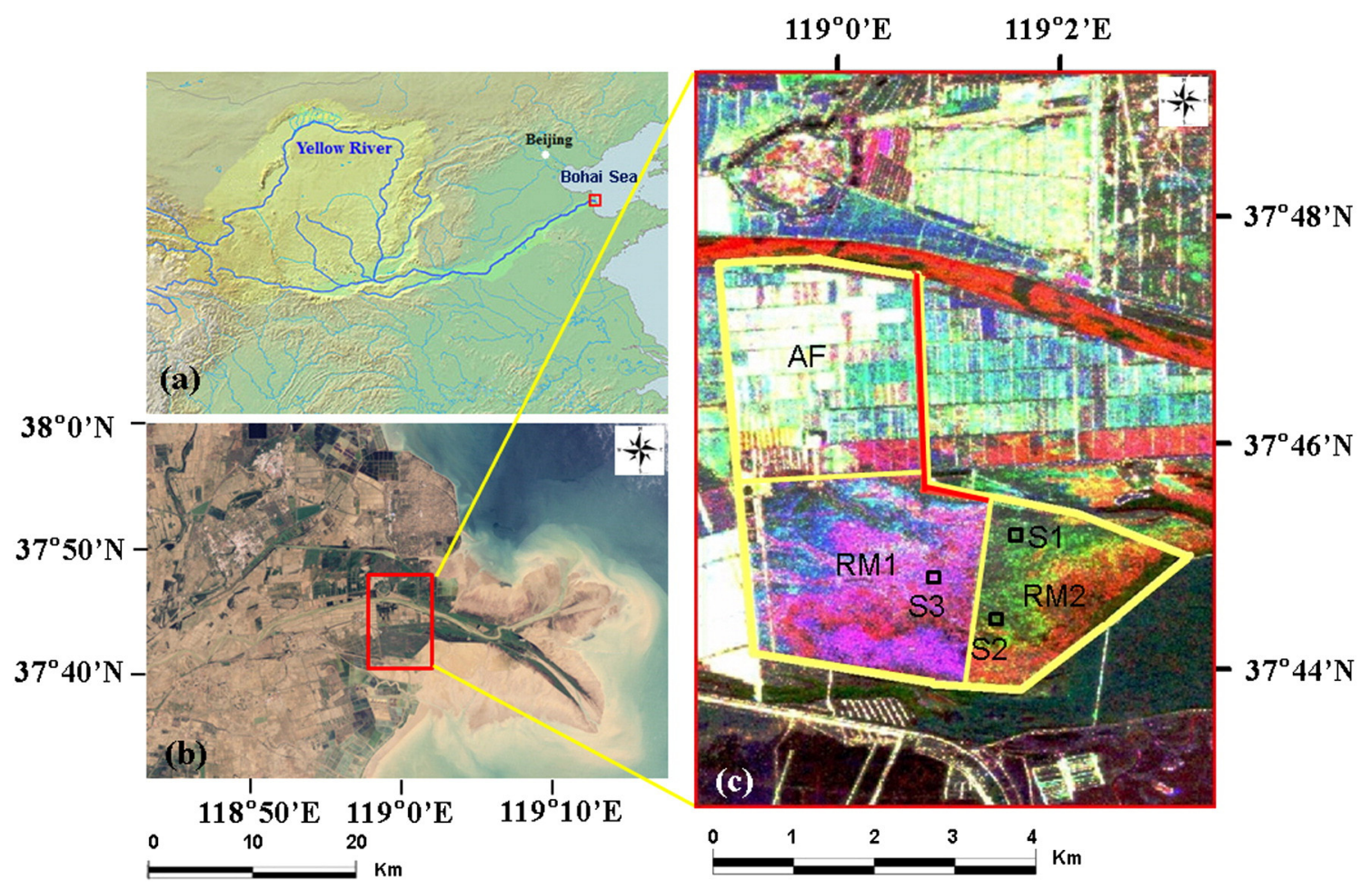

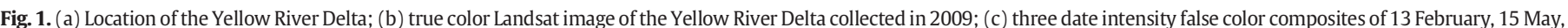

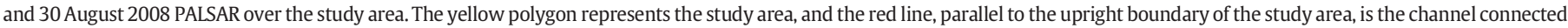

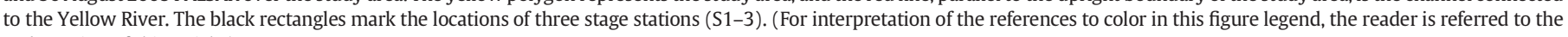
web version of this article.)

Their incidence angle is $34.3^{\circ}$, which is suitable for hydrological application in wetlands (Kim et al., 2013).

The data acquisition mode on 3 January and 18 February, 2010 is FBS (Fine Beam Single) at $\mathrm{HH}$ polarization, and the acquisition mode of the rest of the data is FBD (Fine Beam Dual) at $\mathrm{HH}$ and HV polarization. The FBD data at HH polarization uses half the range bandwidth of FBS data, but shares the same center frequency with FBS data which makes it possible to process mixed FBS and FBD interferometric pair. To generate interferograms between FBS and FBD data, we applied a range oversampling to FBD data and then coregistered FBS SLC data and FBD oversampling scene to a common geometry (Werner, Wegmüller, Strozzi, Wiesmann, \& Santoro, 2007). The gathered data was in HH polarization, which has a stronger double-bounce backscatter associated with reed stems in marsh and is more suitable for wetland application than other polarizations (Kim et al., 2014).

\subsection{Water level from field investigation}

Water level was collected at the same time as SAR data acquisition by the Odyssey capacitive water level logger (Dataflow Systems, 2013) at 3 investigation sites, as revealed in black rectangles in Fig. 1(c). Chinese Vertical Datum 1985 was adopted as our reference vertical datum to obtain absolute water level observations. These three stage stations were installed at a region with high coherence, and they were implemented to calibrate water level information of RM1 and RM2 respectively. Two stage stations were employed in RM2 and one stage station was employed in RM1. Blue, red and green lines in Fig. 3(a) represent water level observations collected by these three stage stations respectively. The three stations show clearly seasonal variations. Water level generally reaches its peak in August, and decreases greatly from November to next February. (a)

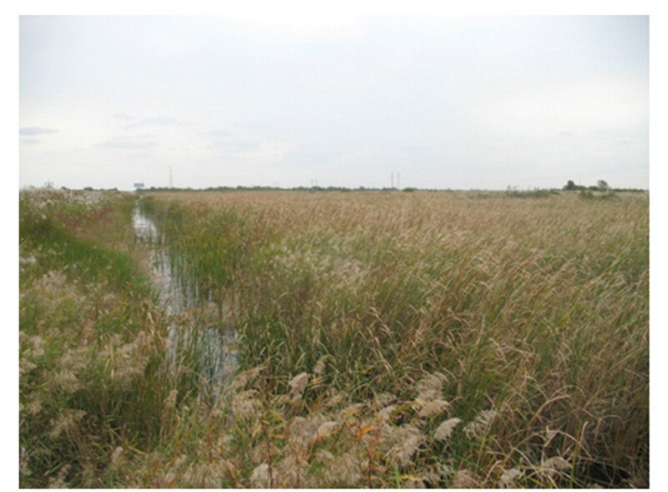

(b)

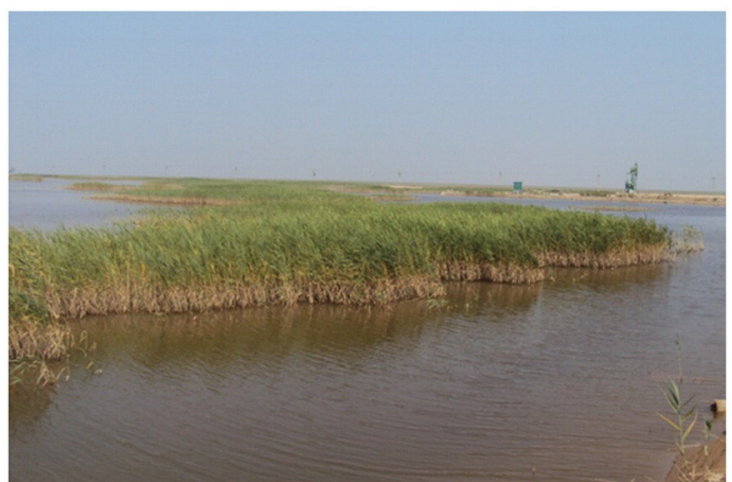

Fig. 2. Pictures of reed marsh wetlands, (a) dense reed in shallow area; (b) sparse reed in deep area. 

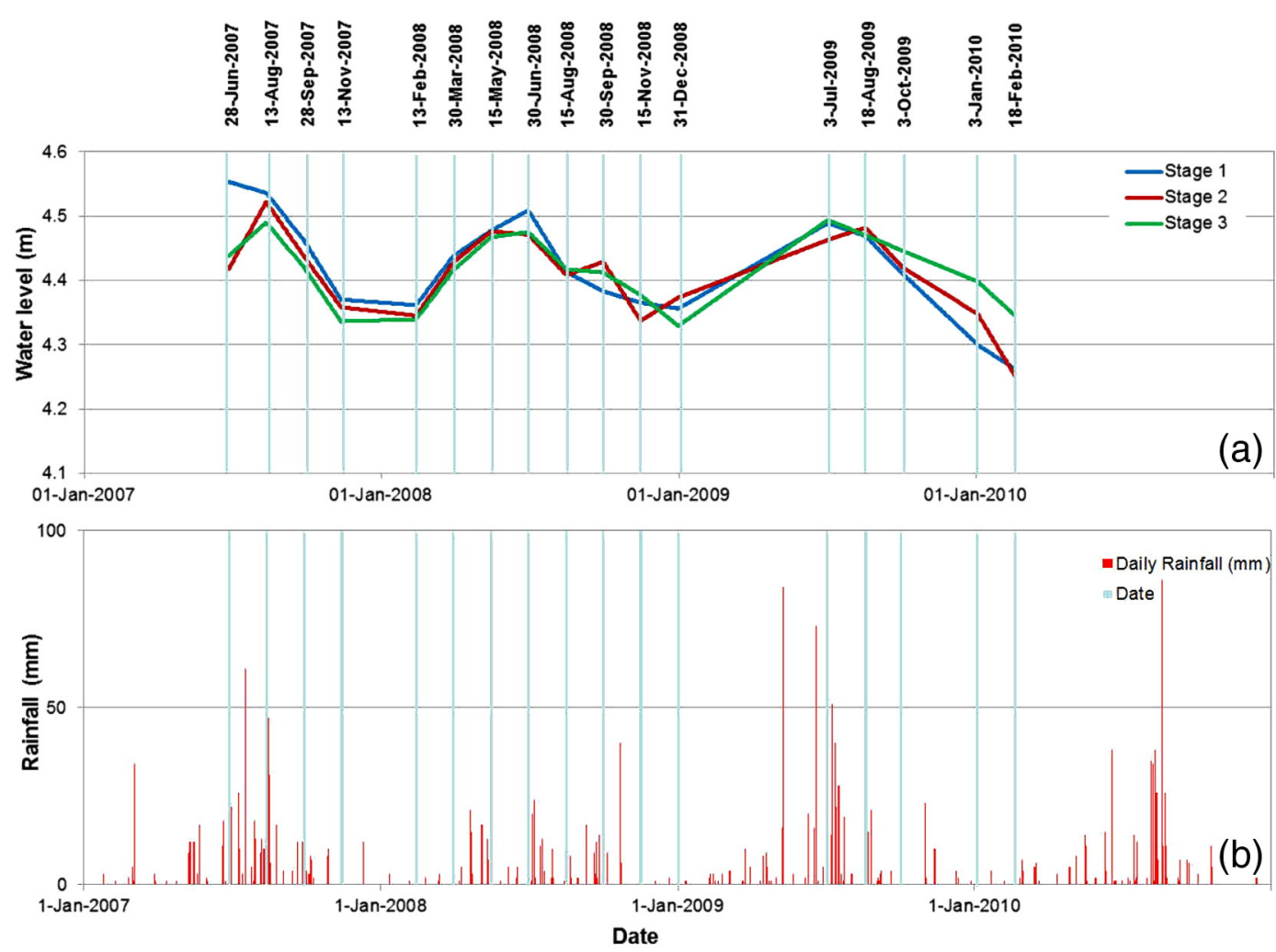

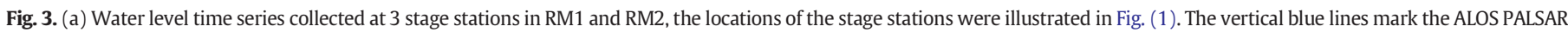

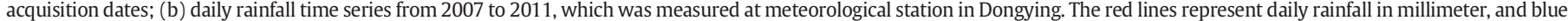
lines reveal SAR data acquisition date. (For interpretation of the references to color in this figure legend, the reader is referred to the web version of this article.)

\subsection{Water depth from field investigation}

At the same time, the team from Beijing Normal University has measured water depth on 30 May, 11 August and 30 August 2008 respectively. Water depths were measured with a GSK-4 Portable Digital Ultrasonic Sounder with $0.05 \mathrm{~m}$ precision for each spot positioned by GPS. Sampling sites were set up according to water depth gradient to gather dense water depth data in RM2. Most of the investigation sites were on the north-half part of RM2, and just a few investigations were located on the south-half part. The southeast boundary has the greatest water depth, and most boundaries have relatively great water depth. Meanwhile there is relatively shallow area in the middle of RM2, where the density of reed is high.

It should be noted that water depth measurements and SAR data were not acquired on the same dates. Table 2 made a comparison between acquisition dates of water depth measurements and SAR data. The SAR data listed in Table 2 were the ones which were acquired closest to dates of water depth investigation. Considering the acquisition temporal difference, we should take account of precipitation and evapotranspiration when using field investigation to estimate water depth on acquisition dates of SAR data in RM2.

Table 2

Comparison of acquisition date of water depth measurement and SAR data.

\begin{tabular}{lll}
\hline Nr. & Water depth measurement & SAR data \\
\hline 1 & 30 May 2008 & 15 May 2008 \\
2 & 11 Aug. 2008 & 15 Aug. 2008 \\
3 & 30 Aug. 2008 & 30 Sept. 2008 \\
\hline
\end{tabular}

\subsection{Meteorological data}

We also collected meteorological data from meteorological station in Dongying. The distance between the study area and the meteorological station in Dongying is $40 \mathrm{~km}$. According to acquired meteorological data, we generated daily rainfall time series from 2007 to 2011 (Fig. 3(b)). Severe rain events always occur from June to September every year, especially in 2007 and 2009. From November to next February, there were seldom rainfall events.

\subsection{Pre-processing}

We generated average intensity image from multi-temporal coregistered amplitude images, and then converted intensity image to backscatter coefficient image using parameters supplied in ALOS PALSAR leader files as shown in Fig. 4(a). Under assumption of constant plant height, canopy density and incidence angle, backscatter intensity of flooded reed marsh wetland is influenced by water level changes on HH polarized L-band SAR image. For reed marsh at an intermediate stage of growth (plant height is about $100 \mathrm{~cm}$ ), the increase of water level implies that the scattering center of the double bounce scattering mechanism moves toward the upper part of the stem, while the attenuating vegetation layer becomes thinner. Consequently the double bounce backscattering becomes the dominant effect and causes an increase of scatter coefficient. Kandus, Karszenbaum, Pultz, Parmuchi, and Bava (2001); Kasischke et al., 2003. Backscatter intensity of reed marsh is just at a medium level (see Fig. 4(a)), and has a great variety because of the influence of water level change and plant life cycle evolution. The average backscatter coefficient in RM2 is $-18 \mathrm{~dB}$, which is lower than average backscatter coefficient in RM1 and AF. 

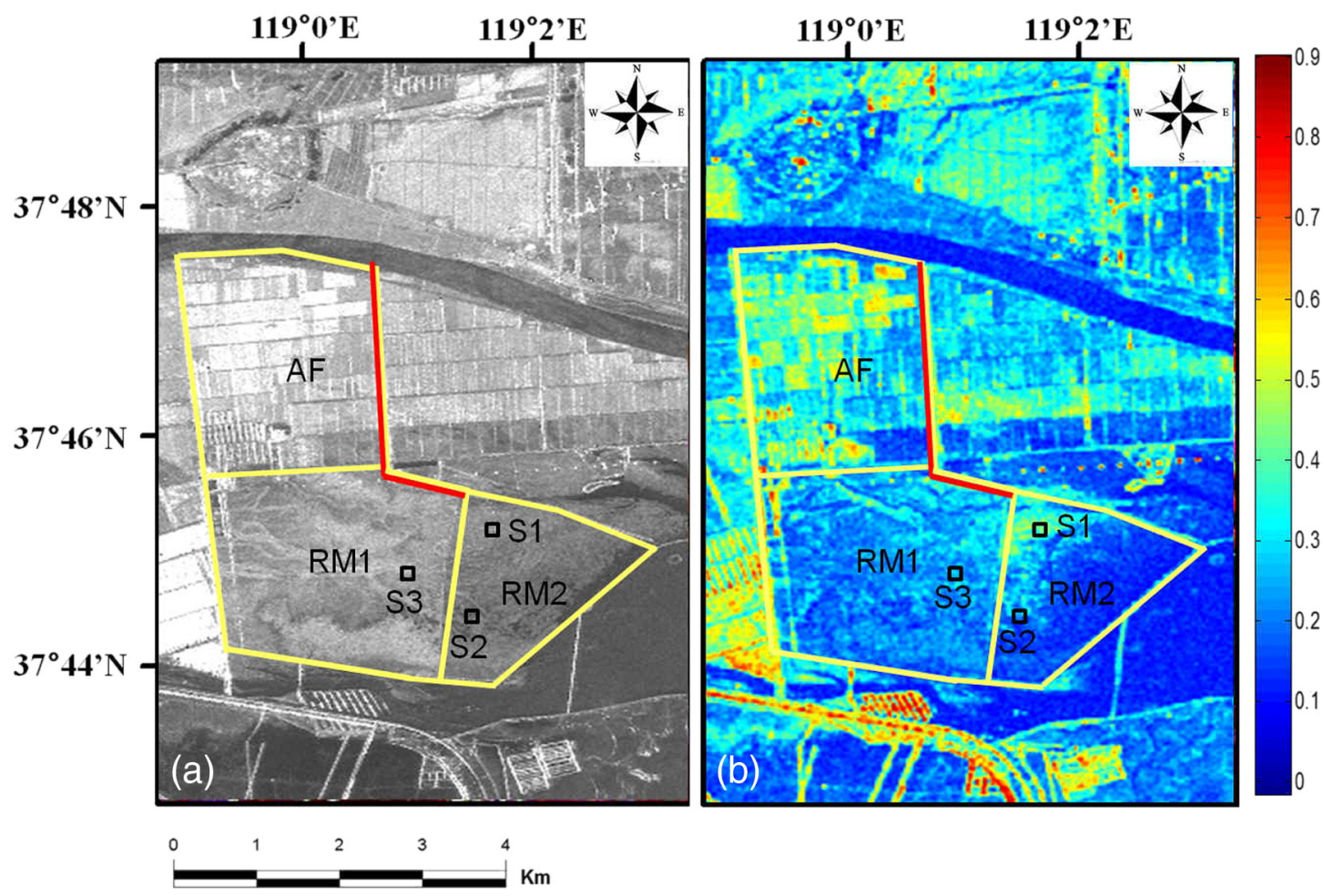

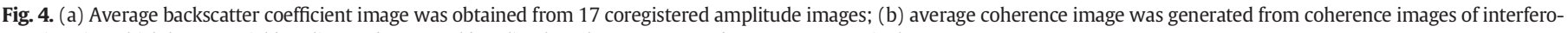
metric pairs which have spatial baseline and temporal baseline less than $2000 \mathrm{~m}$ and one year respectively.

We also generated average coherence image Fig. 4(b) from coherence images of interferometric pairs which have spatial baseline and temporal baseline less than $2000 \mathrm{~m}$ and one year respectively. The temporal and spatial baseline thresholds were set in this way because the coherence of coastal wetlands is strongly dependent on the temporal baseline and much less on the perpendicular one in L-band $\mathrm{HH}$ polarized interferograms (Kim et al., 2013). Fig. 4(b) illustrates that agricultural field has the higher coherence in the two different kinds of land covers. The west part of RM2 has a relatively high coherence, which is higher than 0.3 and promises the quality of interferometric phase and hydrological information estimated in RM2. Maintained coherence over reed marshes reveals that the majority of the returned L-band SAR signal must be from the interaction with reed trunks and the water surface beneath.

\section{Methodology}

\subsection{Water level estimation using DSI technique}

The flowchart of the DSI technique adopted in this manuscript can be presented schematically as follows:
1. Based on interferometric coherence, form an optimized interferogram network composed of all the interferograms beyond a certain coherence threshold.

2. Identify statistically homogeneous pixels by applying the twosample AD test to amplitude data vectors.

3. Implement spatial adaptive filtering on homogeneous pixels to reduce noise and enhance fringe visibility on distributed scatterers.

4. Estimate absolute water level from filter interferograms with assistant of stage data.

Fig. 5 illustrates the flowchart of hydrological information estimation based on the DSI technique.

\subsubsection{Optimal interferogram network}

Target rotation resulting from wind, change of vegetation height and canopy density leads to temporal decorrelation of natural targets in coastal wetland. Only interferograms with high coherence can promise the quality of interferometric phase, and it is crucial to generate optimal network connecting all the interferograms with high coherence for hydrological information estimation. In original PSI processing, interferometric phase is generated by referring all images to a common master

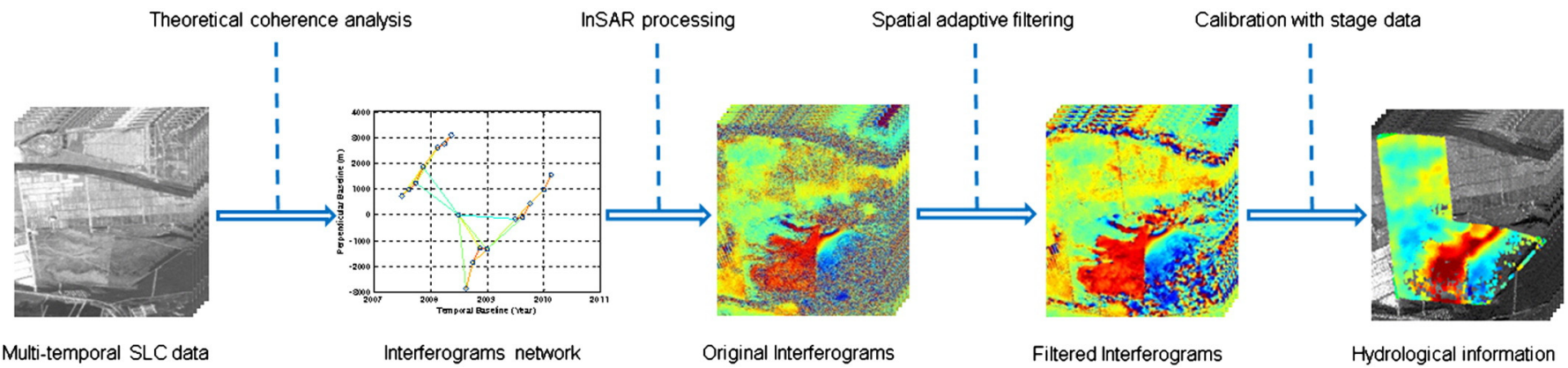

Fig. 5. Flowchart of hydrological information estimation based on DSI technique. 
acquisition (Ferretti et al., 2001). We set up an interferogram selection method to identify the network of multi-temporal interferograms forming an optimal connection in the spatial/temporal baseline plane. The optimal network was formed based on MST (Minimum Spanning Tree) and coherence threshold. Basic connection was constructed by MST algorithm (Perissin \& Wang, 2012; Refice, Bovenga, \& Nutricato, 2006), and then interferogram with high coherence were added into the network. Theoretical interferometric coherence was estimated according to the equation (Hooper, 2006),

$$
\begin{aligned}
\gamma & =\gamma_{\text {spatial }} \gamma_{\text {temporal }} \gamma_{\text {doppler }} \gamma_{\text {noise }} \\
& =\left(1-\frac{B_{\text {perp }}}{B_{\text {perp_c }}}\right)\left(1-\frac{\Delta t}{T_{c}}\right)\left(1-\frac{\Delta f d c}{f d c_{c}}\right)\left(\frac{S N R}{1+S N R}\right)
\end{aligned}
$$

where $\gamma_{\text {spatial }}, \gamma_{\text {temporal }}, \gamma_{\text {doppler }}$ and $\gamma_{\text {noise }}$ denote spatial, temporal, Doppler and thermal noise components, respectively. $B_{\text {perp }}, \Delta t$ and $\Delta f d c$ represent spatial, temporal, and Doppler centroid baseline respectively. $B_{\text {perp_c }} i$ is the critical baseline at which the interferometric correlation becomes zero and is calculated according to Hanssen (2001), $f d c_{c}$ is $1521 \mathrm{~Hz}$ for PALSAR FBD mode. $T_{c}$ is a temporal decay constant, and is 2500 days for wetland according to Kim's research (Kim et al., 2013). SNR (signal-tonoise ratio) equals to $6.95 \mathrm{~dB}$ for PALSAR FBD mode. Interferograms with theoretical coherence higher than 0.6 were added to the network constructed in spatial and temporal planes.

Based on the above mentioned regulations, we formed the optimal interferogram network in the spatial/temporal baseline plane (Fig. 6). It should be noted that the perpendicular baselines of PALSAR are correlated with the acquisition time (Samsonov, 2010), which led to separation of acquired SAR data in the spatial/temporal plane. The collected data are separated into two subsets (data collected before and after June, 2008) and one isolated data (data collected on June 30, 2008). To maintain the connectivity of the network, we should promise there is at least one connection between the isolated data and each subset. 28 interferograms were finally generated for water level change estimation. Table 3 listed the detail parameters of interferometric pairs. The range of their spatial perpendicular baselines extends from $41 \mathrm{~m}$ to $1570.75 \mathrm{~m}$. The range of their temporal baselines extends from 46 days to 414 days. It should be noted that the interferogram with the maximum temporal baseline has a very short spatial perpendicular baseline $(110 \mathrm{~m})$.

\subsubsection{Identification of homogeneous pixels}

Wetland is characterized by a typical kind of distributed scatterers, which involve a coherent sum of many independent small scatterers (no dominant scatterer) within a resolution cell and then dominant scattering mechanism can be described as a complex circular Gaussian radar return (Bamler \& Hartl, 1998). Based on the stack of coregistered and calibrated L-Band $\mathrm{HH}$ polarization SAR amplitude images, we could identified for each pixel the statistically homogenous pixels (SHPs) surrounding it by testing if the two corresponding random processes belong to the same distribution in statistics. Compared to other test methods, Anderson-Darling (AD) test has been proven to be the most effective method (Parizzi \& Brcic, 2011). AD test puts more weight on the tails of the distributions, which is very important in radar application where the distribution's tail plays an important role, leading to a lower rate of the second kind of error in the hypotheses (Scholz \& Stephens, 1987). For two samples $p$ and $q$ on a stack of co-registered and calibrated SAR amplitude images, the test statistics $A_{p, q}^{2}$ is defined as

$A_{p, q}^{2}=\frac{N}{2} \sum_{x \in\left\{x_{p, i}, x_{q, i}\right\}} \frac{\left(\widehat{F}_{p}(x)-\widehat{F}_{q}(x)\right)^{2}}{\widehat{F}_{p q}(x)\left(1-\widehat{F}_{p q}(x)\right)}$

where $\widehat{F}_{p}(x)$ and $\widehat{F}_{q}(x)$ are empirical cumulative distribution functions for $p$ and $q$, and $\widehat{F}_{p q}(x)$ is the empirical cumulative distribution function of the pooled distribution of the two samples. The asymptotic distribution was given by Anderson and Darling (1952) for $N \rightarrow \infty$, while the quantiles' approximations for finite sample size are given by Pettitt (1976).

We first define for each pixel $P$ an estimation window centered on $P$, and then apply the two-sample GOF test between every pixel within the estimation window for each center pixel $P$ at a given level of significance. We selected all the pixels that can be considered as statistically homogenous, and abandoned the statistically homogenous image pixels that were not connected to P directly through other SHP. Finally the

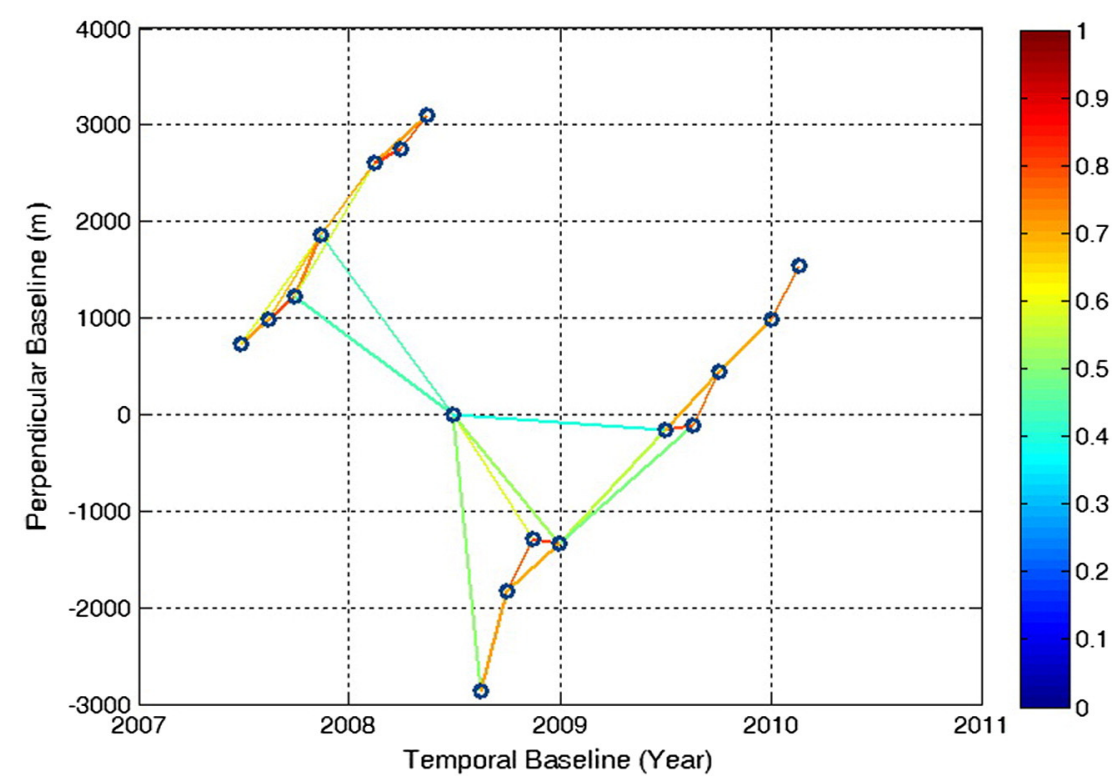

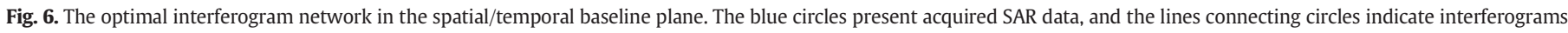

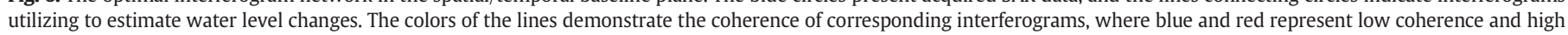
coherence respectively. (For interpretation of the references to color in this figure legend, the reader is referred to the web version of this article.) 
Table 3

List of ALOS-PALSAR interferometric pairs.

\begin{tabular}{|c|c|c|c|c|c|c|c|c|c|}
\hline $\mathrm{Nr}$. & Master & Slave & $B_{\text {perp }}{ }^{a}$ & $\Delta t^{\mathrm{b}}$ & $\mathrm{Nr}$. & Master & Slave & $B_{\text {perp }}$ & $\Delta t$ \\
\hline 1 & 28 Jun. 2007 & 13 Aug. 2007 & 251.86 & 46 & 15 & 30 Jun. 2008 & 31 Dec. 2008 & 1324.01 & 184 \\
\hline 2 & 28 Jun. 2007 & 28 Sept. 2007 & 486.42 & 92 & 16 & 30 Jun. 2008 & 3 Jul. 2009 & 110.17 & 414 \\
\hline 3 & 28 Jun. 2007 & 13 Nov. 2007 & 1122.01 & 138 & 17 & 15 Aug. 2008 & 30 Sept. 2008 & 1031.04 & 46 \\
\hline 4 & 13 Aug. 2007 & 28 Sept. 2007 & 234.56 & 46 & 18 & 15 Aug. 2008 & 15 Nov. 2008 & 1570.75 & 92 \\
\hline 5 & 13 Aug. 2007 & 13 Nov. 2007 & 870.15 & 92 & 19 & 30 Sept. 2008 & 15 Nov. 2008 & 539.70 & 46 \\
\hline 6 & 28 Sept. 2007 & 13 Nov. 2007 & 635.58 & 46 & 20 & 30 Sept. 2008 & 31 Dec. 2008 & 498.48 & 92 \\
\hline 7 & 28 Sept. 2007 & 13 Feb. 2008 & 1383.97 & 138 & 21 & 15 Nov. 2008 & 31 Dec. 2008 & 41.22 & 46 \\
\hline 8 & 28 Sept. 2007 & 30 Jun. 2008 & 1214.45 & 276 & 22 & 31 Dec. 2008 & 3 Jul. 2009 & 1172.63 & 276 \\
\hline 9 & 13 Nov. 2007 & 13 Feb. 2008 & 748.38 & 92 & 23 & 31 Dec. 2008 & 18 Aug. 2009 & 1213.85 & 230 \\
\hline 10 & 13 Nov. 2007 & 15 May 2008 & 1229.71 & 184 & 24 & 3 Jul. 2009 & 18 Aug. 2009 & 52.20 & 46 \\
\hline 11 & 13 Feb. 2008 & 30 Mar. 2008 & 134.81 & 46 & 25 & 3 Jul. 2009 & 3 Oct. 2009 & 607.97 & 92 \\
\hline 12 & 13 Feb. 2008 & 15 May 2008 & 481.32 & 92 & 26 & 18 Aug. 2009 & 3 Oct. 2009 & 555.77 & 46 \\
\hline 13 & 30 Mar. 2008 & 15 May 2008 & 346.51 & 46 & 27 & 3 Oct. 2009 & 3 Jan. 2010 & 531.48 & 92 \\
\hline 14 & 30 Jun. 2008 & 15 Nov. 2008 & 1282.79 & 138 & 28 & 3 Jan. 2010 & 18 Feb. 2010 & 564.23 & 46 \\
\hline
\end{tabular}

a Spatial perpendicular baseline

b Temporal baseline.

SHPs for pixel P can be used for pixel-wise post processing, such as interferometric phase filtering and coherence estimation.

Fig. 7 presents the results of statistically homogenous pixels (SHPs) selection (in red) for the green pixel with a detection window of $40 \times 40$ pixels by goodness-of-fit test. Fig. 7(a) shows amplitude image covering the bottom land forest, which is an artificial forest and has regular spatial structure with relatively higher backscatter coefficient. We can see that 131 pixels were identified as SHPs, and they all lay on the same agricultural field. From our other experiments, a great amount of homogenous pixels can also be found in reed marsh area.

\subsubsection{Spatial adaptive filtering}

Based on the SHPs identified in the above step, a spatial adaptive filtering can be applied to improve fringe visibility in the interferograms and increase the signal-to noise ratio (Goel \& Adam, 2013). The adaptive filtered interferogram value from the $j$ th SAR image $S_{j}(p)$ and the $k$ th SAR image $S_{k}(p)$ for pixel point $P$ is estimated as:

$I_{j, k}(P)=\frac{1}{|\Omega|} \sum_{p \in \Omega} S_{j}(p) \cdot S_{k}^{*}(p) \cdot e^{-i \varphi_{\text {ref }}}$

where * indicates the conjugation, $\Omega$ is the set of identified SHP and $\varphi_{\text {ref }}$ is the reference phase, which includes flat earth and topographic phase.
We made a comparison of boxcar multilooking and spatial adaptive algorithm as applied on an interferogram covering the study area. Fig. 8(a) illustrates the amplitude image over the area, and Fig. 8 (d) shows $1 \times 5$ multilooked interferogram which is exploited for the following filtering. Fig. 8(b) and Fig. 8(e) are the coherence and interferogram estimate after $4 \times 4$ pixels boxcar multilooking respectively. Fig. 8(c) and Fig. 8(f) is coherence and interferogram estimate after adaptive spatial filtering based on Anderson-Darling test respectively. It can be obviously found that adaptive filtering has a better effect on reducing speckle noises on interferogram than boxcar filtering, and at the same time adaptive filtering preserve the spatial resolution. On Fig. 8(c) and Fig. 8(f), the coherence and interferometric phase quality has been improved greatly, and it is easy to separate levee from reed marsh and agricultural field.

\subsubsection{Absolute water level estimation}

On every unwrapped interferogram, water level change $\Delta h_{t_{i}, t_{j}}(x, y)$ for every coherent pixel $(x, y)$ from time $t_{i}$ to time $t_{j}$ can be estimated according to the following equation.

$\Delta h_{t_{i}, t_{j}}(x, y)=\Delta h_{t_{i}, t_{j}}\left(x_{0}, y_{0}\right)+\frac{\lambda \Delta \phi_{t_{i}, t_{j}}}{4 \pi \cos \theta_{i n c}}+n$

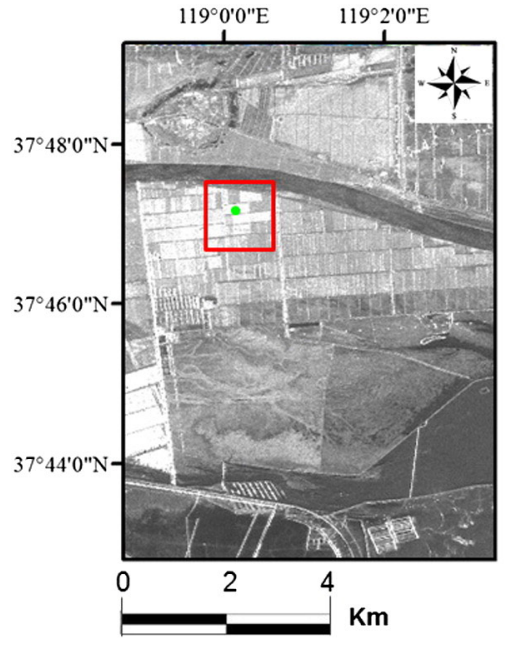

(a)

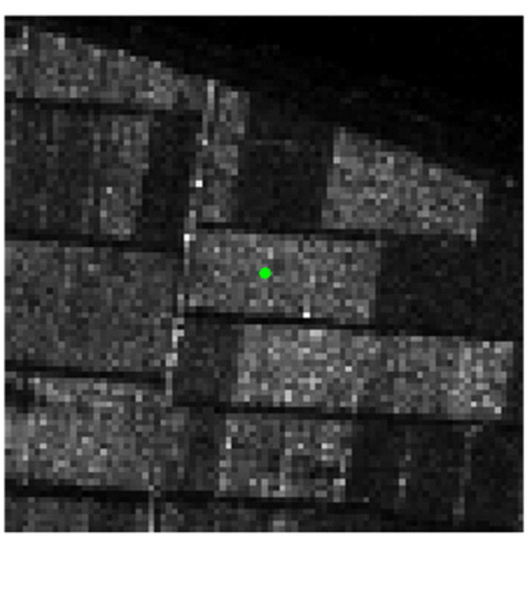

(b)

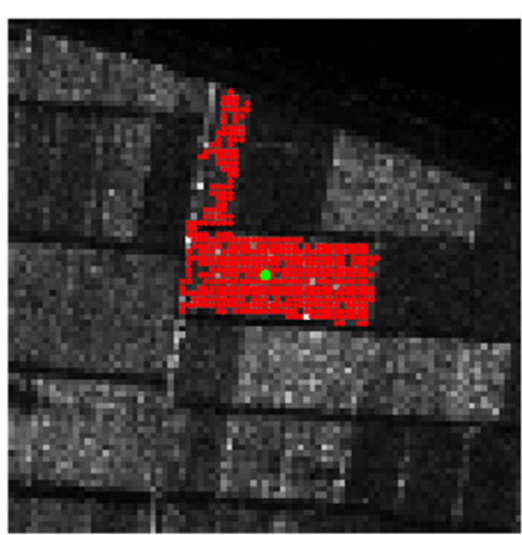

(c)

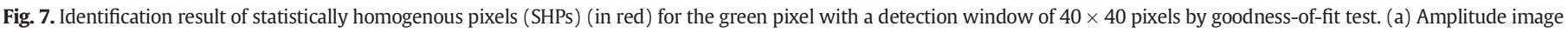

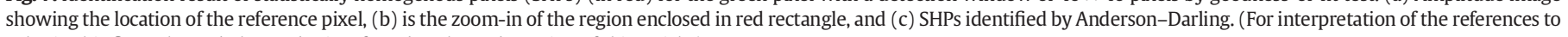
color in this figure legend, the reader is referred to the web version of this article.) 


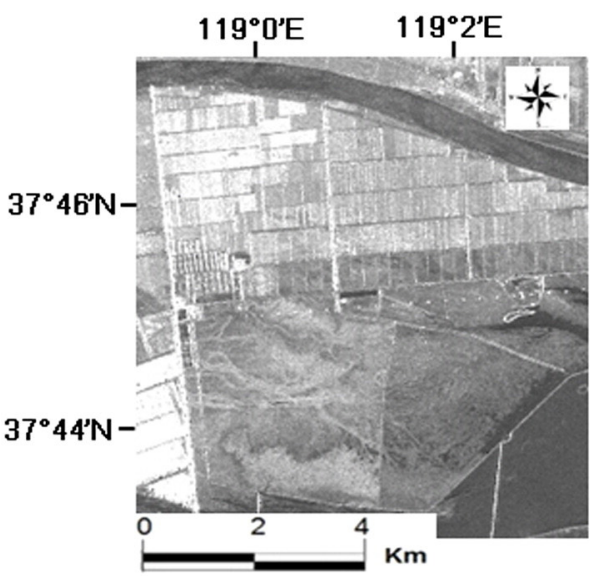

(a)

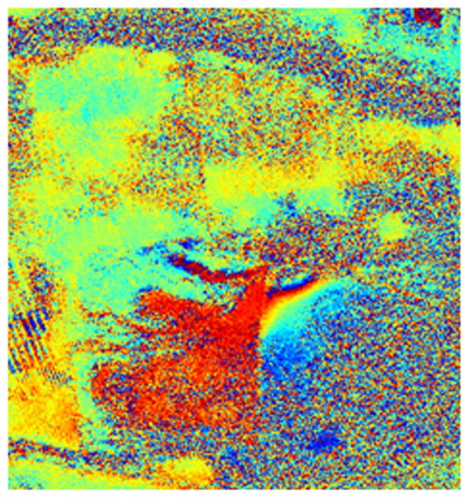

(d)

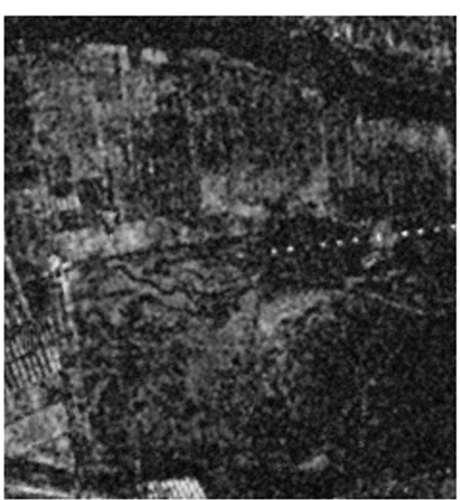

(b)

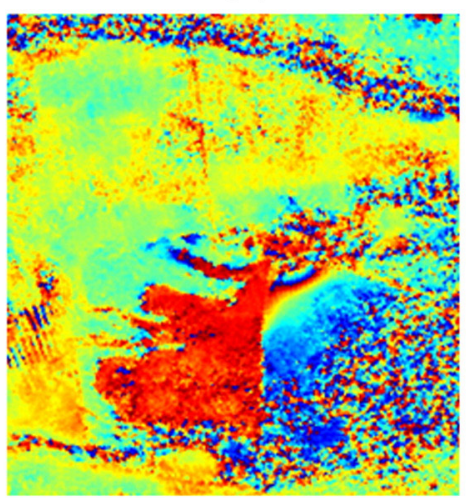

(e)

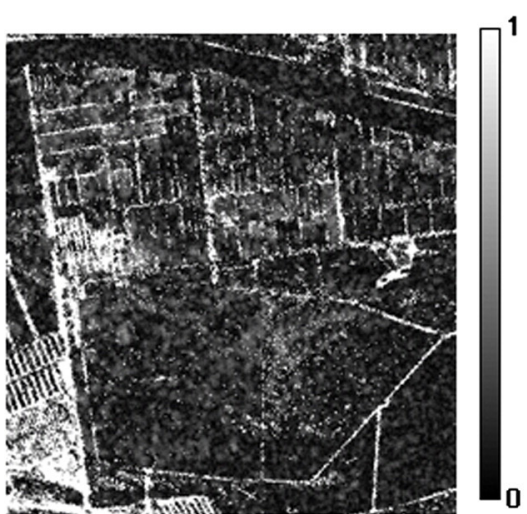

(c)

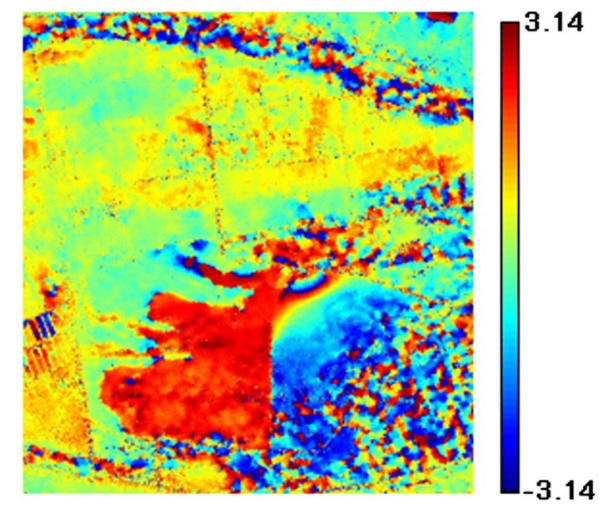

(f)

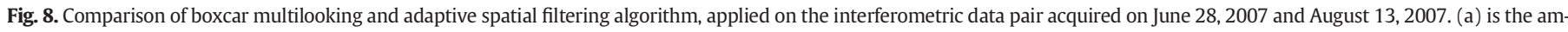

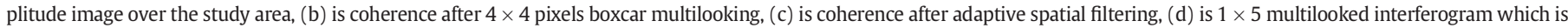

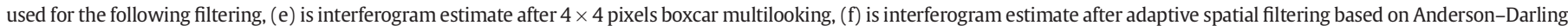
test. The interferometric fringe within the reed marsh is due to managed flow.

where $\theta_{\text {inc }}$ is the SAR incidence angle, $\lambda$ is the SAR wavelength, $\Delta \phi_{t_{i}, t_{j}}$ represents the phase variation between point $(x, y)$ and reference point $\left(x_{0}\right.$, $y_{0}$ ) on unwrapped interferogram, and $n$ represents noise term. Stage stations were selected as reference point $\left(x_{0}, y_{0}\right)$, and relative water level change $\Delta h_{t_{i}, t_{j}}\left(x_{0}, y_{0}\right)$ can be generated from stage data.

In this paper, an L1-norm based technique was used to retrieve relative water level changes from unwrapped differential interferograms. L1-norm based SBAS technique for water level retrieval is discussed in more detail in Appendix A. In reed marshes, there might be several decorrelated areas separating the coherent patches. This often introduces parameter estimation errors. L1-norm cost function can estimate water level changes with robust outlier rejection (Goel \& Adam, 2012).

It should be noted that only relative water level changes can be obtained from unwrapped differential interferometric phase, so ground hydrological observations are needed to calibrate InSAR observation and obtain absolute water level estimation (Lu \& Kwoun, 2008; Wdowinski et al., 2008). To estimate absolute water level, relative water level series should first be generated by integrating derived relative water level changes between time-adjacent acquisitions. Then absolute water levels time series can be estimated by tying the relative series to reference water levels. There were always linear offsets between InSAR derived relative water level and stage data (Wdowinski et al., 2008). By comparing water level series collected from InSAR observation and stage data, we can estimate linear offsets between the two methods. After the removal of linear offset, we generated InSAR derived absolute water level series.

\subsection{Water depth estimation}

It should be noted that water depth represents the distance between from bottom and top surface of a body of water in this paper. Meanwhile, water level represents the level of the surface of a body of water. Under the assumption that topography under water is constant at one point, it can be inferred that water depth changes equal to water level changes over the entire observation time period. Then, a simple formula between water depth and water level can be set up.

$d(t)-d\left(t_{0}\right)=l(t)-l\left(t_{0}\right)$

where $d$ and $l$ represent water depth and water level respectively, and $t_{0}$ is the reference time. As illustrated in Fig. 1, RM2 is blocked by levees and only connected to the Yellow River through a tiny channel. Flows due to gate operation, which occurs once a year when the Yellow River has a high water level during summer, could not lead to large amount of sediment or great change of the topography under water in RM2. Then, water depth in RM2 can be estimated from water level according to the following equation.

$d(t)=l(t)-l\left(t_{0}\right)+d\left(t_{0}\right)$

Since we obtained dense water depth observation from field investigation, water level time-series could be transferred to water depth time-series based on this formula. 


\section{Results}

\subsection{Water level time-series}

According to the optimal network illustrated in Fig. 6, we generated 28 interferograms with relatively high coherence. Fig. 9 shows the 28 wrapped interferograms after adaptive spatial filtering over the study area. Most of the wrapped interferograms have continuous fringes on them, and only a few interferograms have some discontinuous fringes and speckle. From Fig. 9, it can be seen that hydraulic regime of RM1 and RM2 is relatively simple.

Filtered interferograms illustrate that vertical changes of water level can be clearly reflected from InSAR fringe patterns in wetlands environments. Wetland management agency had irrigated the wetlands on June 28,2007 , and the managed flow led to obvious fringes on related interferograms, which contain more fringes than the other interferograms. Meanwhile, flat water conditions occur in August, September and November 2007. Red-blue-green alternation over RM2 in Fig. 9 (1)-(3) reveals decreasing water levels from upstream to downstream, and InSAR derived differential change in water level caused by managed flow was $20.8 \mathrm{~cm}$ between upstream and downstream.

Different land covers revealed different fringe patterns on filtered interferograms. Fig. 9 illustrates that there were obvious interferometric fringes in reed marsh wetlands (RM1 and RM2) in some interferograms, and most of the time there were no obvious fringes in agricultural field. Agricultural field was highly correlated with no interferometric fringes during the whole temporal interval of data acquisition, meaning that there was no deformation or water level change on agricultural field. Some parts of RM1 were seldom inundated according to field investigation, and had almost the same interferometric phase as agricultural field. The rest part of RM1 was continuously flooded all year round. There are clear irregular boundaries on the two parts, which can be easily recognized in some interferograms in Fig. 9 and also on amplitude images illustrated in Fig. 1(c). RM1 is not directly connected to the Yellow River through any channels, so rainfall and evapotranspiration have significant impacts on water level in RM1. It results from the fact that there was almost no flow leading to obvious fringe patterns in differential interferograms in RM1.

Then, we estimated absolute water level sequence from filtered interferograms by bonding the relative water level sequence to reference water level. Field investigation revealed there was no obvious hydrological change caused by rainfall and human-induced flow on November 15,2008 . So we defined a reference water level during flat water level conditions on November 15, 2008 to expand this knowledge from finite locations where stage data are available for all pixels. Fig. 10 shows InSAR derived absolute water level time series from June 28, 2007 to February 18, 2010.

Fig. 10 illustrates that there was no water level change at agricultural field because it was seldom flooded. Most of the time, RM1 and RM2 have a similar water change trend, where water level gets the highest values in summer and the lowest values in winter respectively. The blue and yellow arrows in water level map on June 28, 2007 mark the input and output stage gate respectively, and the dominant managed flow direction is from northwest to southeast. The absolute water level image on June 28, 2007 has a good agreement with the flow pattern. When there was a managed flow caused by gate operation, the neighborhood area immediately had obvious water level change.

It was managed flow and heavy rainfall that result in higher water level in summer, especially on August 13, 2007. Fig. 3(b) illustrates that there were severe rainfall events occurring between June 28 and August 13,2007 , which led the great increase of water level. Fig. 3(b) also shows that low rainfall led to the low water levels in winter. It should be noted that the water level image on September 28, 2007 illustrates a great water level difference between RM1 and RM2, and we suspect that the difference was caused by an observation error of stage data in RM1.

According to field investigations, daily average temperature in February 18, 2010 was below zero degrees in the study area, and low temperature unavoidably led to freezing of water in reed marshes. The InSAR observations did not reveal the ground truth at that time, and we deleted the water level image on February 18, 2010 from the hydrological sequence.
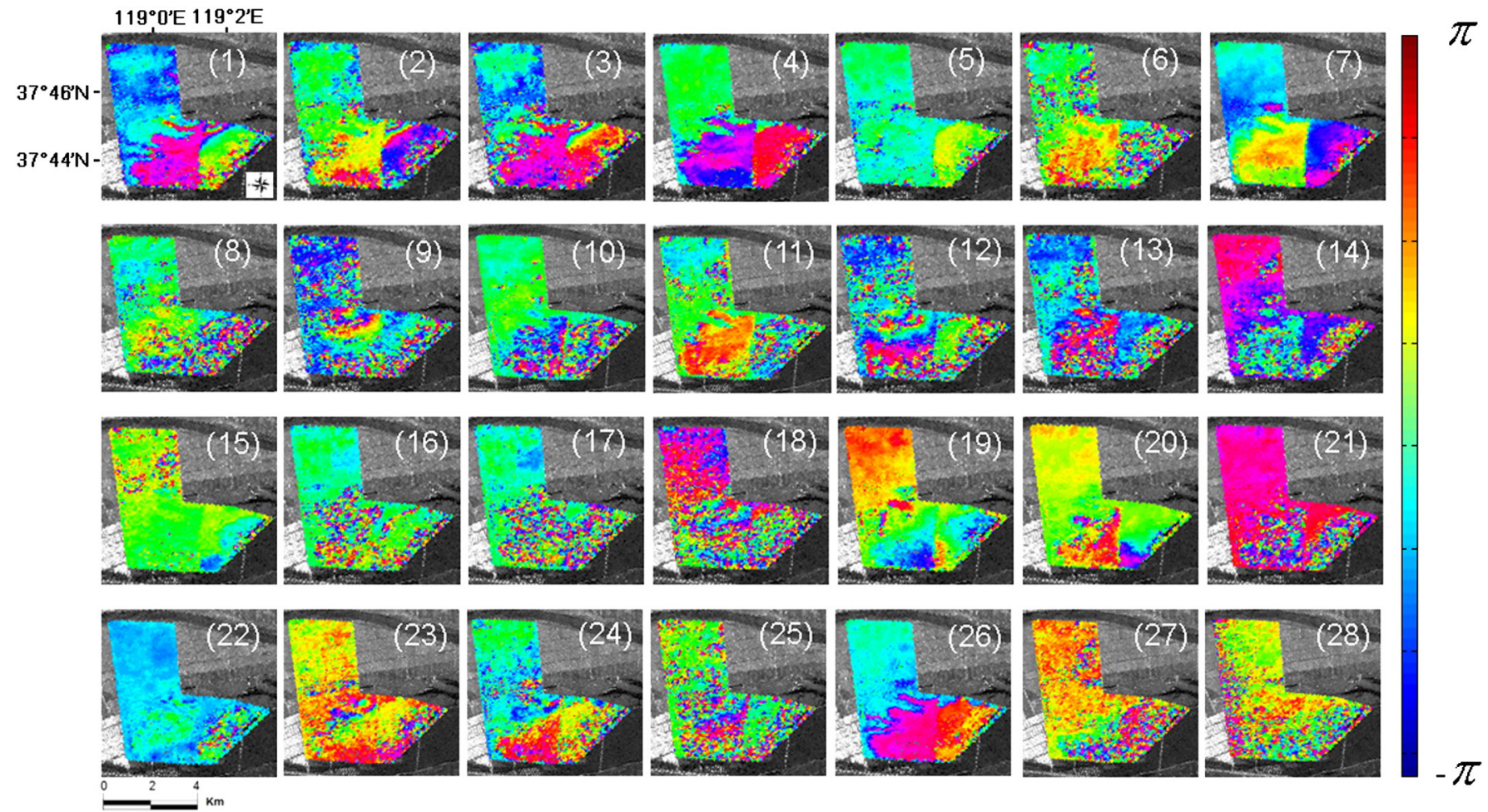

Fig. 9. 28 wrapped interferograms over the study area after flat earth correction and topographic phase removal. The background is average amplitude image over the study area. 

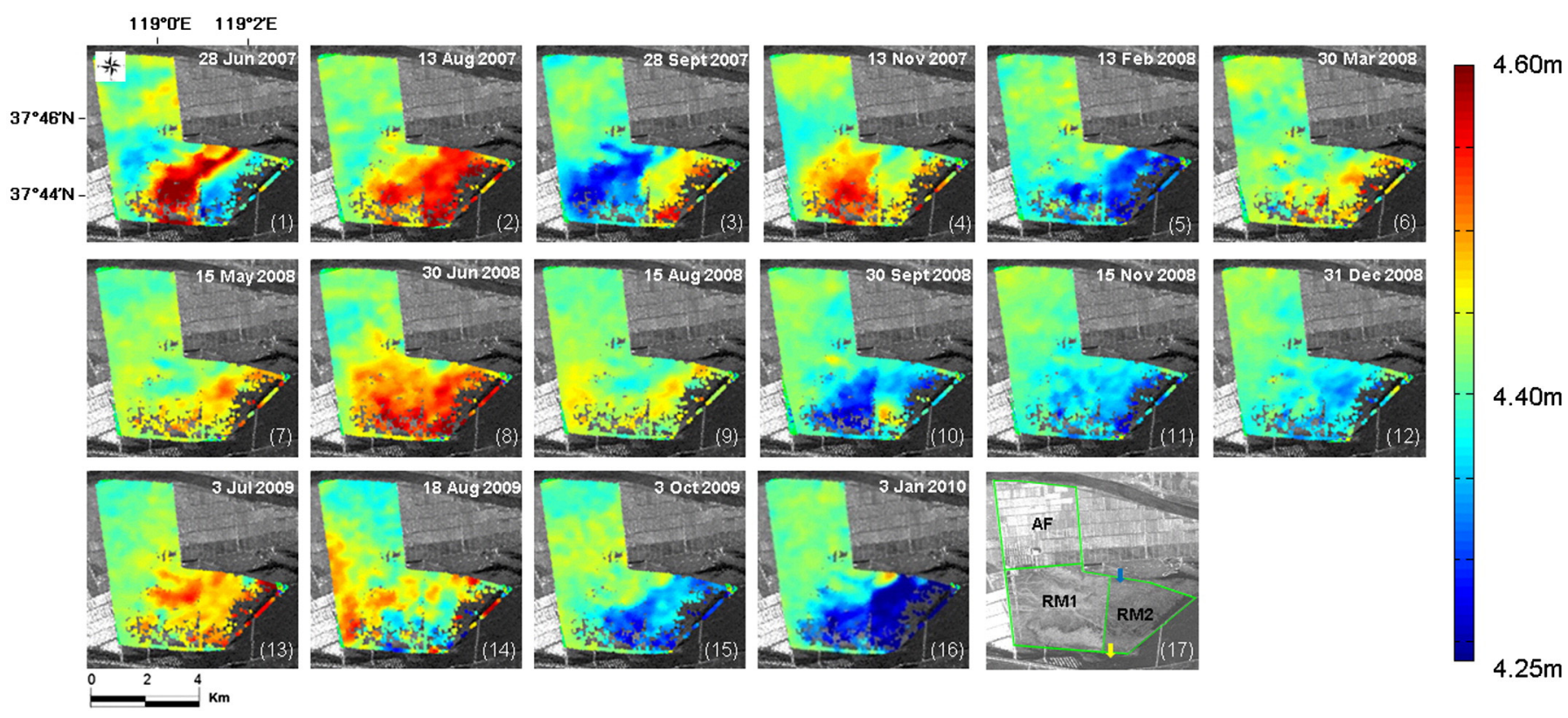

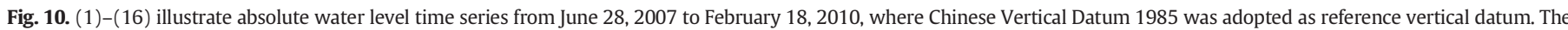

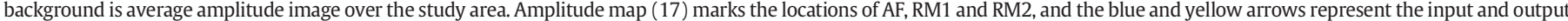
stage gate respectively. (For interpretation of the references to color in this figure legend, the reader is referred to the web version of this article.)

\subsection{Water depth time-series}

\subsubsection{Reference water depth image generation}

As illustrated in Eq. (6), we need to select one water depth investigation as the reference to derive water depth from InSAR derived water level observations. The water depth investigation on August 15, 2008 was chosen as the reference observation in this paper. Meanwhile, the acquisition date of water depth measurement was August 11, 2008. Then, we should take managed flow, rainfall and evapotranspiration into account when we estimate water depth on SAR acquisition date.
Fig. 3(b) shows that there was no precipitation from August 11 to August 15, 2008, and field investigation shows that there was also no managed flow, since daily evapotranspiration was about $3 \mathrm{~mm}$ in August over reed marsh (Jia et al., 2009) and total evapotranspiration was about $12 \mathrm{~mm}$ in 4 days. Taking $12 \mathrm{~mm}$ evapotranspiration into account, water depth on August 15, 2008 can be estimated from ground measurements on August 11, 2008. By interpolating sparse water depth observations to a regular grid using kriging interpolation algorithm, we can obtain high resolution map (Fig. 11) of water depth on August 15, 2008. The small black dots on Fig. 11 illustrate the locations of field

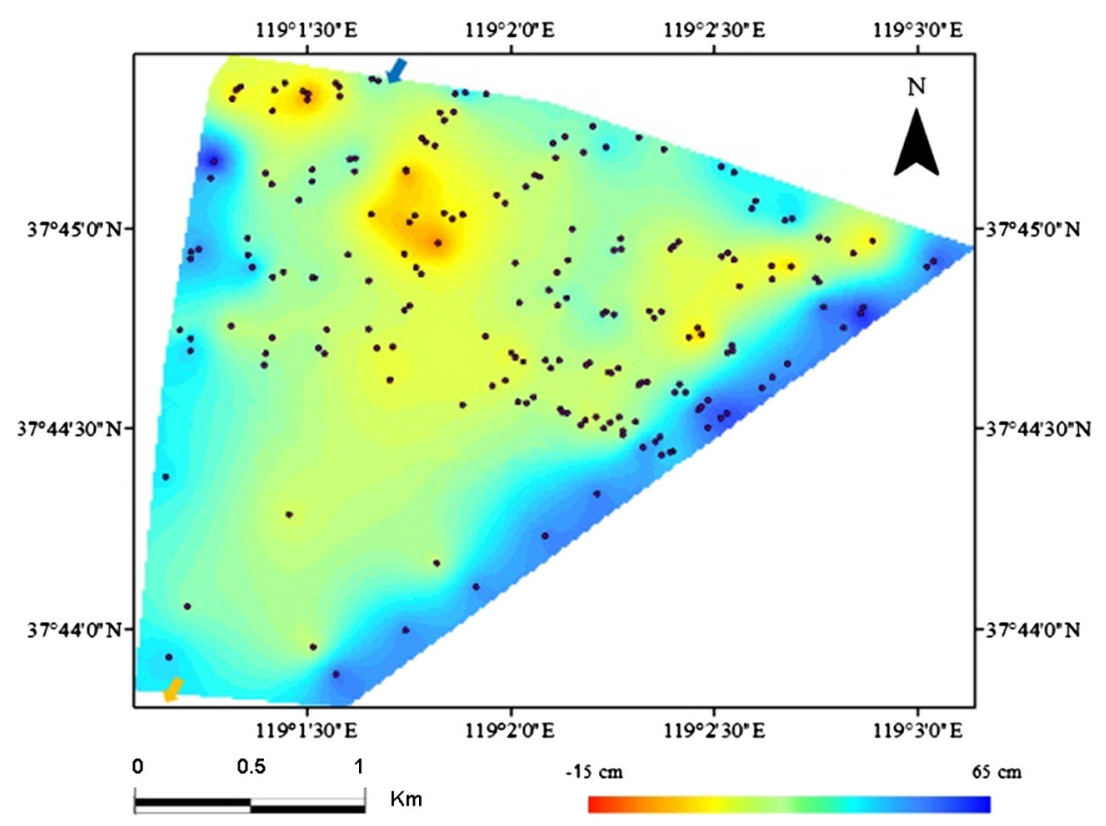

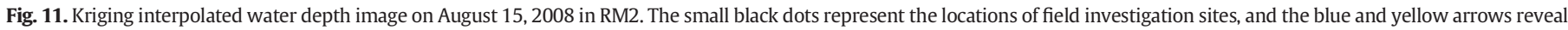

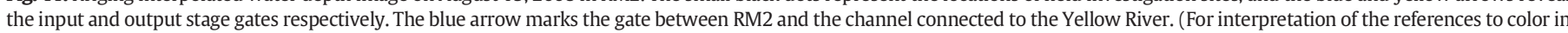
this figure legend, the reader is referred to the web version of this article.) 
investigation sites. Most of the investigation sites were on the north-half part of RM2, and just a few investigations sites located on the south-half part.

The high resolution water depth image (Fig. 11) shows a great deal of hydrological information in RM2. It should be noted that the water depth ranges from $-8.4 \mathrm{~cm}$ to $53.6 \mathrm{~cm}$, with negative values representing groundwater level below ground surface. The southeast boundary and the northwest corner are the deepest and the shallowest parts of RM2 respectively. Meanwhile, there are also some relatively shallow areas in the middle of RM2, where the average value of water depth is $10.2 \mathrm{~cm}$ and the density of reed is high.

\subsubsection{Water depth time sequence generation}

Based on kriging interpolated water depth image on August 15, 2008, we generated water depth sequence from June 2007 to January 2010 according to Eq. (6). Fig. 12 reveals InSAR derived water depth sequence from June 28, 2007 to January 3, 2010 in RM2. It should be noted that the water depth ranges from $-15 \mathrm{~cm}$ to $65 \mathrm{~cm}$. Most of RM2 was below water in summer, especially in August 13, 2008. Then water depth decreased greatly from September to next March. In winter, RM2 was above water except for the southeast corner. Water depth increased greatly on June 28, 2007 around the upstream stage gate, and at the same time some downstream part of reed marsh was still above water level because the managed flow had not reached there.

\section{Discussion}

\subsection{Water level estimation using DSI technique}

Our interferometric results (Fig. 9) proved that it's possible to utilize L-band SAR interferometry to monitor water level change in reed marshes wetlands. Double bounce is the dominant backscattering mechanism over managed reed marshes on $\mathrm{HH}$ polarization L-band SAR data, and an increase of canopy density results in an increase of double-bounce scattering and leads to an increase of total backscattering signal. At the same time, water level also has a positive impact on radar backscatter amplitude of reed marsh (Kim et al., 2014). Comparing to interferograms formed by X-band or C-band data, L-band interferograms can keep a relatively high coherence level with a long time span. All the interferograms listed in Table 3, even some interferometric pairs with temporal baseline over one year, have an average coherence over 0.2 in reed marsh. It promises the quality of interferometric phase and makes it possible to implement long term interferometric analysis over reed marsh.

To derive long term hydrological information from interferometric stack, it's necessary to form a network which utilizes interferograms effectively. Because the coherence level of C-band data is strongly dependent on temporal baseline, Hong et al. (2010b) only adopted interferograms with temporal baseline shorter than 48 days. For L-band data, interferometric phase can be maintained over six month and even longer in herbaceous wetlands (Kim et al., 2013). It means some interferograms with relatively long temporal baseline can also be utilized to derive water level changes. An initial network constructed using MST algorithm could promise interferogram network's connectivity. Meanwhile theoretical coherence was assigned as a weight to quantify interferograms' goodness and added high coherence interferograms to maximize the coherence of the total network. The dispersions of spatial and temporal baselines allow high-precision estimates of hydrological variation.

Our technique is particularly appropriate to estimate parameters in coastal wetlands because it is focused on homogeneous interferometric phase analysis on distributed scatterers in coastal wetlands. Although our study was limited to coastal wetlands in the Yellow River Delta, it also has a great implication potential for other coastal wetland regions worldwide. Distributed scatterers are dominant scatterers in coastal wetlands, such freshwater marshes, freshwater swamps, and coastal mangrove. These distributed scatterers share similar reflectivity values, and can be determined by performing statistically homogeneous pixel analysis (Ferretti et al., 2011). Although distributed scatterer was more suitable for high resolution sensor, our SHP detection result (Fig. 7) illustrated distributed scatterers can also be found on medium resolution image, such as ALOS PALSAR data. An adaptive spatial phase filtering algorithm can greatly improve fringe quality on distributed scatterers (Goel \& Adam, 2012).

There are two reasons leading to water level change over coastal wetlands in the Yellow River Delta (Wdowinski et al., 2008). The first one is managed flow, and the second one is rainfall and evapotranspiration. Because the study area is very small and surrounded by levees, there was no obvious water level variation along the dominant flow direction even after a significant rainfall event. Only after a large upstream flow influx, it can be expected to detect changes reflecting differential changes in water levels. The red line on Fig. 13(c) marks the flow
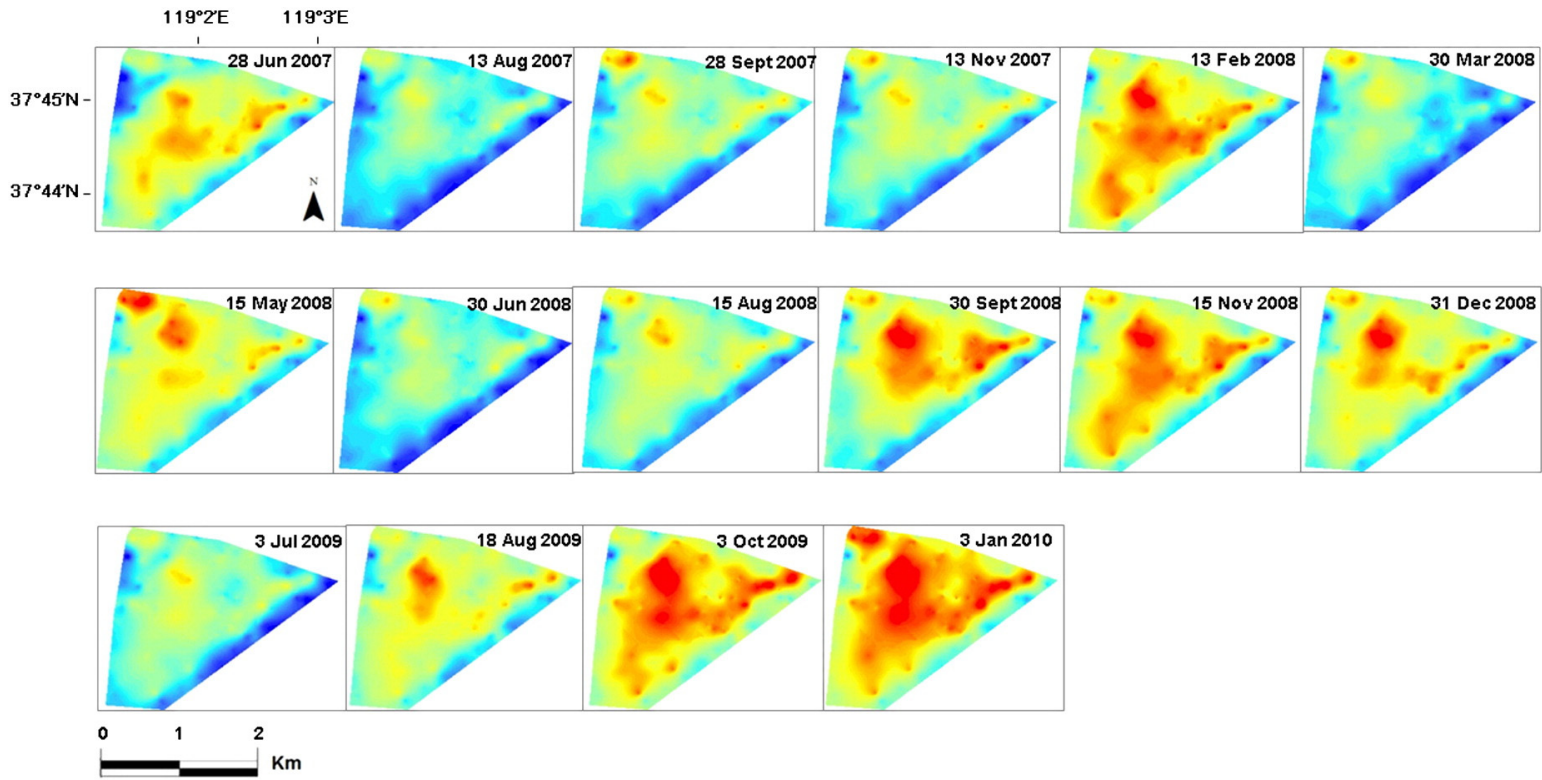


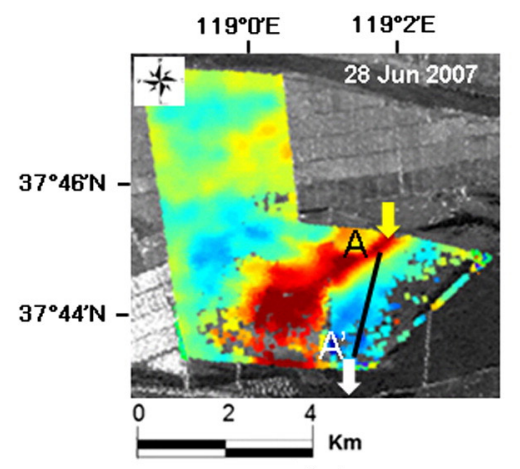

(a)

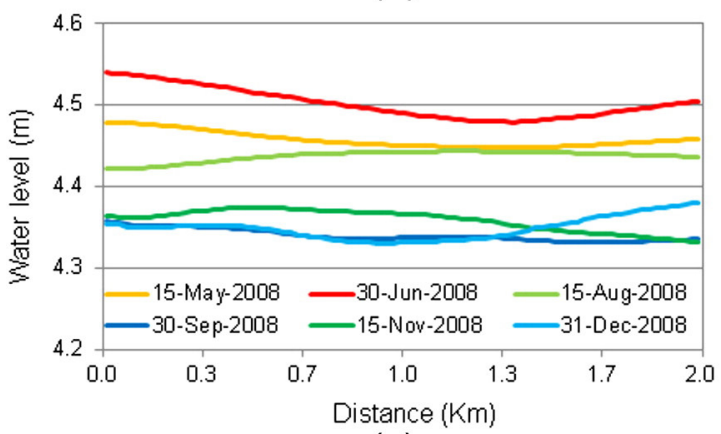

(c)

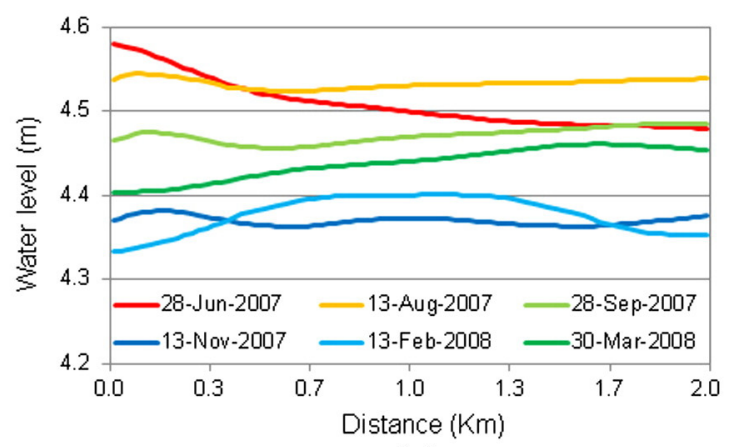

(b)

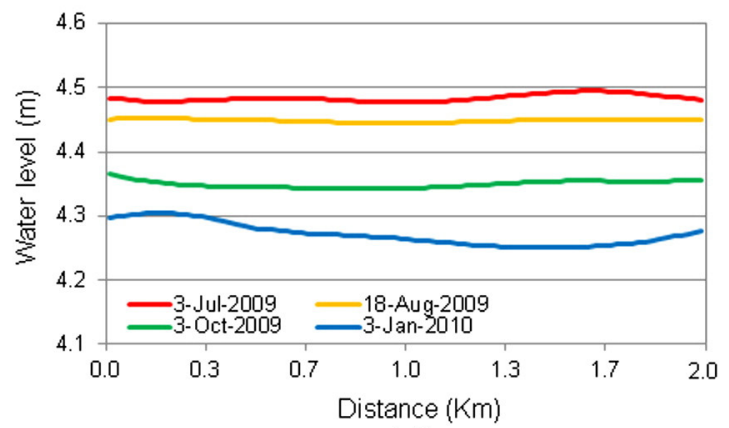

(d)

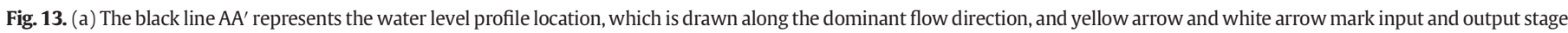

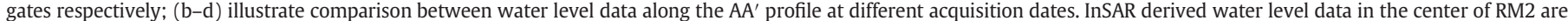

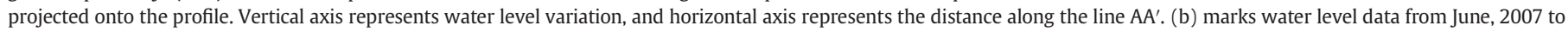

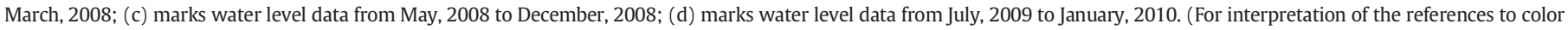
in this figure legend, the reader is referred to the web version of this article.)
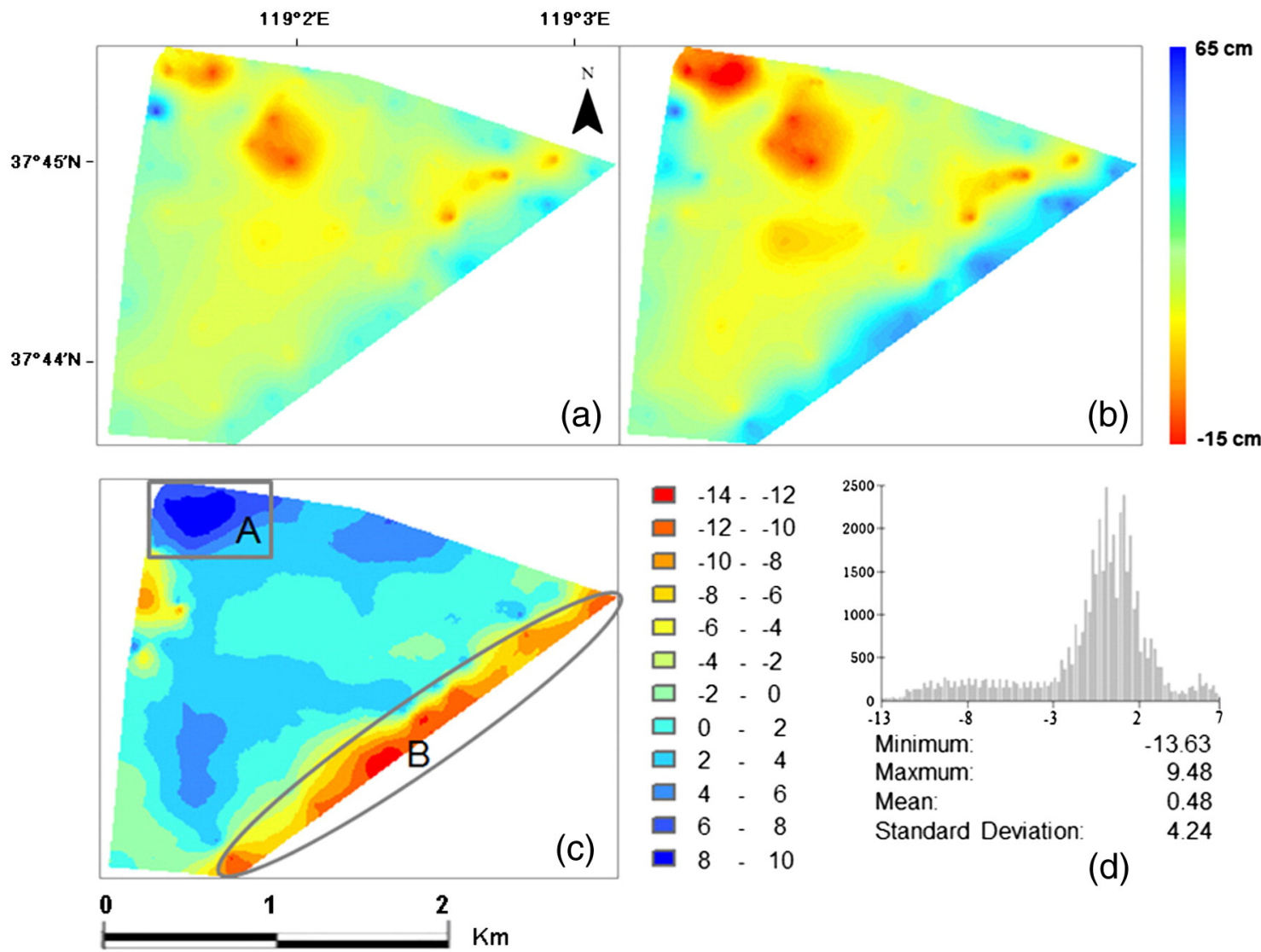

(d)

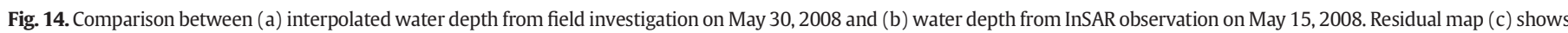
deviation and (d) reveals histogram of deviation. (For interpretation of the references to color in this figure, the reader is referred to the web version of this article.) 
cause by gate operation on June 28,2007 , and water level decreases gradually along the dominant flow direction $\mathrm{AA}^{\prime}$. InSAR derived water level observation clearly illustrate seasonal variation of water level. Seasonal variation of water level has a good agreement with seasona variation of rainfall events. Severe rainfall events concentrated in summer, while water level also reached the peak in summer (from June to August), which were represented by red and yellow lines in Fig. 13(b)-(d). Meanwhile, water level and rainfall events hit bottom simultaneously in winter (from November to next February), which were marked by deep green and blue lines in Fig. 13(b)-(d).

\subsection{Water depth time-series}

InSAR derived water depth has a good agreement with field investigation, as shown in Fig. 14. We evaluated the accuracy of InSAR derived water depth by comparing interpolated water depth obtained from ground investigation on May 30, 2008 and from InSAR observation on May 15,2008 . Taking account of water depth changes caused by rainfall (32 $\mathrm{mm}$ according to collected meteorological data) and evapotranspiration ( $60 \mathrm{~mm}$ according to Jia et al. (2009)), we generated residual map obtained by two different methods. Fig. 14 compares interpolated water depth from field investigations and interpolated water depth from InSAR observation.

The residual map (Fig. 14(c)) reveals that deviations between two kinds of observation are below $4 \mathrm{~cm}$ in shallow water area with dense reed. The histogram of residual map, Fig. 14(d), illustrates that the mean value of residual is $0.48 \mathrm{~cm}$ and the standard deviation is $4.24 \mathrm{~cm}$, and suggests the potential of DSI technique in long term water depth time-series estimation in inundated dense reed. The highest residual values appear in open water area and long dry reed marsh, $-13.63 \mathrm{~cm}$ and $9.48 \mathrm{~cm}$, respectively. Rectangle A and ellipse B represent the two areas with the highest residual values in Fig. 14(c). The small area in rectangle A, which is in red in Fig. 14(a) and (b), was seldom flooded and always above water level. The dominant backscattering mechanism is volume scattering in the small area, and it is not practical to utilize InSAR technique to estimate hydrological information in this area. Ellipse B in Fig. 14(c) represents open water area with sparse reed. The dominant backscattering mechanism is surface scattering and radar backscattering intensity is very weak in this area. Serious decorrelation in open water area unavoidably leads to water level error of water depth in InSAR observations.

Our methodology has a potential to be applied to natural swamp and mangrove, which was subjected to the natural fluctuation. In general for L-band interferograms, the coherence over swamp and mangroves has higher value than coherence over herbaceous wetlands (Kim et al., 2013). It means interferogram can maintain interferometric phase with longer time span over natural swamp and mangrove than over reed marsh. The most important difference between managed and natural wetlands lies in the interferometric fringe pattern. In the natural flow areas, such as marshland, fringes are irregular and have a low fringe rate (Wdowinski et al., 2008). Because natural wetlands are subject to the natural tidal fluctuation, their interferometric fringe pattern reflects water level changes resulted from ocean tide.

On the other hand, the application of our presented technique depends on acquisition of L-band SAR data. The ALOS-2 was launched on May 24, 2014, and the L-band Synthetic Aperture Radar-2 (PALSAR-2) aboard ALOS-2, using the $1.2 \mathrm{GHz}$ frequency range, will have a spotlight mode ( 1 to $3 \mathrm{~m}$ ) and a high resolution mode ( 3 to $10 \mathrm{~m}$ ) (Japan Aerospace Exploration Agency, 2013). It would be beneficial to increase the number and spatial resolution of acquisitions over wetland areas, and promises the future applications of DSI technique on long term water depth monitoring.

Water depth time-series can be used to estimate ecological water requirements based on habitat response to water level and evaluate the ecological performance of wetland restoration (Cui et al., 2009b; Li et al., 2009). Ecologists can also use water depth time-series to set up relationships between water depth and coverage and height of reed, and then simulate spatial distribution of various habitats for various water depths. Meanwhile, wetlands management for water birds commonly involves manipulation of water depth, and water depth has strong effect on densities of bird and plant species in wetlands (Colwell \& Taft, 2000; Cui et al., 2010; Jackson \& Colmer, 2005; Laitinen, Rehell, \& Oksanen, 2008; Seabloom et al., 1998). Based on derived long term high spatial resolution maps of water depth, ecologists can measure a wetland's biological and functional integrity. Thresholds for water depths, which are supposed to maintain wetlands in the best quality to comply with ecological management goals, can be determined by quantitative comparison.

\section{Conclusion}

Temporal decorrelation seriously limits the application of Permanent Scatterers technique for estimating long term hydrological information, which is vital for ecologists to evaluate the ecological performance of wetland. To overcome the limitation, we develop a new distributed scatterer technique, which fully utilizes InSAR stack data by forming an optimum interferogram network, and implements spatial adaptive filtering to reduce noise and enhance fringe visibility on distributed scatterers. With stage data for calibration, we derived water level time series from InSAR observation and easily transformed them to water depth. The high resolution map of water depth thus obtained facilitates crucial information to determine ecological water requirement for wetlands and manage wetlands efficiently.

Water depth directly influences the distribution, growth and suitability of specific species. Water depth time series can be used to analyze ecological characteristics of plant communities under different hydrological conditions. With water depth time-series, we can set up relationships between water depth and distribution of various habitats, and calculate optimum water level to keep the wetland ecosystem in suitable and desired conditions. It allows us to make well-informed decisions in the process of management of wetlands, leading ultimately to the improvement in maintenance of ecosystems and thus to sustainable development of wetlands.

\section{Acknowledgments}

We are thankful to the anonymous reviewers and editors for the constructive comments which greatly helped to improve this paper. Suggestions by Bangsen Tian, Zhong Lu, Giosue Andrey Giardino and Yanyan Hua are also greatly appreciated. ALOS PALSAR images are copyright of Japanese Aerospace Exploration Agency (JAXA). This research was supported by funding from the CAS Knowledge Innovation Programme (KZCX2-EW-320), the National Natural Science Foundation of China (41001276, 41431174, U1303285, and 61471358), the China Scholarship Council (201304910028), and the National High-tech R\&D Programme (2011AA120403).

\section{Appendix A. Water level retrieval using an L1 norm based SBAS technique}

We retrieve water level changes from the filtered interferograms using an L1 norm based SBAS technique. Each of the differential interferograms is unwrapped and all coherent pixels are referenced to one pixel with a known water level. The interferogram network forms the following system of equations for every coherent pixel:

$B \Delta h=C \Delta \phi+\Delta h_{0}+n$

where $C=\frac{\lambda}{4 \pi \cos \theta_{\text {inc }}}$, and $\Delta \phi$ is the vector of unwrapped differential interferometric phase values after the spatial adaptive filtering. $B$, described in detail in Berardino et al. (2002), is the matrix defining the formed optimal interferogram network; $\Delta h$ is the vector of unknown relative 
water level changes on coherent pixel $(x, y)$ between time-adjacent acquisitions, and $\Delta h_{0}$ is relative water level changes on reference stage station. $n$ represents noise term including contributions from topographic errors, atmospheric noise, and orbit error. Since the wetland areas are generally flat (elevation varies from 0 to $5 \mathrm{~m}$ ), the effects of topographic errors from the DEM were negligible. Orbit errors (that translate in linear phase fringes across the interferograms) can be compensated by removing perfectly linear trends from the unwrapped interferograms (Poncos et al., 2013).

The SVD method can be utilized to obtain a minimum-norm least squares (LS) solution (L2 norm minimization) of Eq. (7) (Berardino et al., 2002). However, there are always several decorrelated areas, such as open water, separating the coherent patches in coastal wetlands. This often introduces phase unwrapping errors - phase jumps between the different patches, and L2 norm minimization often performs poorly to detect these phase jumps in the unwrapped data. Instead, L1 norm minimization can supply a more robust phase inversion solution, with respect to the often occurring and difficult to detect phase unwrapping errors found in non-urban areas (Lauknes et al., 2011; Goel \& Adam, 2012). In Rodriguez-Gonzalez et al. (2011), L1 network inversion was demonstrated for robust outlier rejection in PSI. A L1 norm solution of water level change is given by:

$\Delta \hat{h}=\arg \min _{h}\left(\sum_{i=1}^{M-1}\left|C \Delta \phi-B \Delta h-\Delta h_{0}\right|_{i}\right)$.

In this manuscript, the algorithm proposed by Barrodale and Roberts (1973) is used for L1 norm minimization. It is a modification of the simplex method of linear programming and is computationally efficient. Then, an additional integration step gives the water level solution.

In SBAS technique, the atmospheric effects are assumed to be totally decorrelated with the deformation changes in time, and it can be estimated and removed by carrying out a spatial low pass and a temporal high pass filtering operation. However, the atmospheric contribution phase removal approach is not possible in the wetland application, because the water level change and atmospheric disturbance are both high-frequency signal in temporal dimension. Thus the final water level time series probably contains some degree of the atmospheric noise (Hong \& Wdowinski, 2014; Hong et al., 2010b).

The atmospheric noise was estimated with the Integrated Wide Area Processor (IWAP) at the DLR processing facilities. IWAP utilizes Numerical Weather Prediction (NWP) to mitigate atmospheric effects in the PSI processing (Adam, Gonzalez, Parizzi, \& Liebhart, 2011; Rodriguez, Adam, Parizzi, \& Brcic, 2013). The atmospheric noise, estimated using IWAP, was in the range of $1.2-4.3 \mathrm{~cm}$ over the study area.

\section{Reference}

Adam, N., Gonzalez, F.R., Parizzi, A., \& Liebhart, W. (2011). Wide area persistent scatterer interferometry: Algorithms and examples. Proceedings of 'Fringe 2011 Workshop', Fringe 2011, Frascati, Italy (pp. 1-4) (19-23 September).

Alsdorf, D., Melack, J.M., Dunne, T., Mertes, L.A., Hess, L.L., \& Smith, L.C. (2000). Interferometric radar measurements of water level changes on the Amazon flood plain. Nature, 404, 174-177.

Alsdorf, D., \& Rodriguez, E. (2005). WatER: The Water Elevation Recovery Satellite Mission, First Mission Document for the WatER Mission. ([Online]. Available: http://www.geology.ohio-state.edu/water/publications.php. (Accessed: 7 November 2014).).

Alsdorf, D., Rodriguez, E., \& Lettenmaier, D. (2007). Measuring surface water from space. Reviews of Geophysics, 45(2)http://dx.doi.org/10.1029/2006RG000197 (p. RG2 002, Dec. 2007).

Alsdorf, D., Smith, L., \& Melack, J. (2001). Amazon floodplain water level changes measured with interferometric SIR-C radar. IEEE Transactions on Geoscience and Remote Sensing, 39, 423-431.

An, S., Li, H., Guan, B., Zhou, C., Wang, Z., Deng, Z., Zhi, Y., Liu, Y., Xu, C., \& Fang, S. (2007). China's natural wetlands: Past problems, current status, and future challenges. AMBIO: A Journal of the Human Environment, 36, 335-342.

Anderson, T.W., \& Darling, D.A. (1952). Asymptotic theory of certain "goodness of fit" criteria based on stochastic processes. The annals of mathematical statistics, 193-212.

Bamler, R., \& Hartl, P. (1998). Synthetic aperture radar interferometry. Inverse Problems, 14, R1-R54.
Bartsch, A., Kidd, R., Pathe, C., Scipal, K., \& Wagner, W. (2007). Satellite radar imagery for monitoring inland wetlands in boreal and sub-arctic environments. Journal of Aquatic Conservation: Marine and Freshwater Ecosystems, 17, 305-317http://dx.doi.org/10. 1002 /aqc.836.

Bartsch, A., Scipal, K., Wolski, P., Pathe, C., Sabel, D., \& Wagner, W. (2006). Microwave remote sensing of hydrology in southern Africa. Proceedings of the 2nd Göttingen GIS \& Remote Sensing Days: Global Change Issues in Developing and Emerging Countries (4-6 October 200).

Barrodale, I., \& Roberts, F. D. (1973). An improved algorithm for discrete L 1 linear approximation. SIAM Journal on Numerical Analysis, 10, 839-848.

Berardino, P., Fornaro, G., Lanari, R., \& Sansosti, E. (2002). A new algorithm for surface deformation monitoring based on small baseline differential SAR interferograms. IEEE Transactions on Geoscience and Remote Sensing, 40, 2375-2383.

Bharati, L., Anand, B., \& Smakhtin, V. (2008). Analysis of the Inter-basin water transfer scheme in India: a case study of the Godavari-Krishna Link. Strategic Analyses of the National River Linking Project (NRLP) on India, 5, 63-78.

Bourgeau-Chavez, L.L., Smith, K.B., Brunzell, S.M., Kasischke, E.S., Romanowicz, E.A., \& Richardson, C.J. (2005). Remote monitoring of regional inundation patterns and hydroperiod in the greater everglades using synthetic aperture radar. Wetlands, 25(1), 176-191.

Colwell, M., \& Taft, O. (2000). Waterbird communities in managed wetlands of varying water depth. Waterbirds, 45-55.

Costanza, R., Kubiszewski, I., Roman, J., \& Sutton, P. (2011). Migration and global environmental change - DR7a. Changes in ecosystem services and migration in low-lying coastal areas over the next 50 years (ㄷ Crown copyright 2011, 42 pp. Review and associated publications may be found at http://www.bis.gov.uk/foresight/).

Cui, B., Hua, Y., Wang, C., Liao, X., Tan, X., \& Tao, W. (2010). Estimation of ecological water requirements based on habitats response to water level in Huanghe River Delta China. Chinese Geographical Science, 20, 318-329.

Cui, B., Tang, N., Zhao, X., \& Bai, J. (2009a). A management-oriented valuation method to determine ecological water requirement for wetlands in the Yellow River Delta of China. Journal for Nature Conservation, 17, 129-141.

Cui, B., Yang, Q., Yang, Z., \& Zhang, K. (2009b). Evaluating the ecological performance of wetland restoration in the Yellow River Delta, China. Ecological Engineering, 35, 1090-1103.

Cui, B., Zhao, X., Yang, Z., Tang, N., \& Tan, X. (2006). The response of reed community to the environment gradient of water depth in the Yellow River Delta. Acta Ecologica Sinica, 26, 1533-1541.

Millennium Ecosystem Assessment (2005). Ecosystems and human well-being: Wetland and water synthesis. Available online: http://www.millenniumassessment.org/ proxy/Document

Ferretti, A., Fumagalli, A., Novali, F., Prati, C., Rocca, F., \& Rucci, A. (2011). A new algorithm for processing interferometric data-stacks: SqueeSAR. IEEE Transactions on Geoscience and Remote Sensing, 49, 3460-3470.

Ferretti, A., Prati, C., \& Rocca, F. (1999). Multibaseline InSAR DEM reconstruction: The wavelet approach. IEEE Transactions on Geoscience and Remote Sensing, 37, 705-715.

Ferretti, A., Prati, C., \& Rocca, F. (2001). Permanent scatterers in SAR interferometry. IEEE Transactions on Geoscience and Remote Sensing, 39, 8-20.

Frappart, F., Calmant, S., Cauhopé, M., Seyler, F., \& Cazenave, A. (2006). Preliminary results of ENVISAT RA-2-derived water levels validation over the Amazon basin. Remote Sensing of Environment, 100, 252-264.

Goel, K., \& Adam, N. (2012). An advanced algorithm for deformation estimation in nonurban areas. ISPRS Journal of Photogrammetry and Remote Sensing, 73, 100-110.

Goel, K., \& Adam, N. (2013). A distributed scatterer interferometry approach for precision monitoring of known surface deformation phenomena. IEEE Transactions on Geoscience and Remote Sensing, 52, 5454-5468.

Gondwe, B.R.N., Hong, S. -H., Wdowinski, S., \& Bauer-Gottwein, P. (2010). Hydrodynamics of the groundwater-dependent Sian Ka'an wetlands, Mexico, from InSAR and SAR data. Wetlands, 30, 1-13.

Hanssen, R.F. (2001). Radar interferometry: Data interpretation and error analysis. Kluwer Academic Publishers.

Higgins, S., Overeem, I., Tanaka, A., \& Syvitski, J.P. (2013). Land subsidence at aquaculture facilities in the Yellow River Delta, China. Geophysical Research Letters, 40, 3898-3902.

Hong, S. -H., \& Wdowinski, S. (2014). Multitemporal multitrack monitoring of wetland water levels in the Florida everglades using ALOS PALSAR data with interferometric processing. IEEE Geoscience and Remote Sensing Letters, 11, 1355-1359.

Hong, S. -H., Wdowinski, S., \& Kim, S. -W. (2010a). Evaluation of TerraSAR-X observations for wetland InSAR application. IEEE Transactions on Geoscience and Remote Sensing, 48 864-873.

Hong, S. -H., Wdowinski, S., Kim, S. -W., \& Won, J. -S. (2010b). Multi-temporal monitoring of wetland water levels in the Florida Everglades using interferometric synthetic aperture radar (InSAR). Remote Sensing of Environment, 114, 2436-2447.

Hooper, A. (2006). Persistent scatterer radar interferometry for crustal deformation studies and modeling of volcano deformation. (Ph.D. thesis) Stanford, Calif: Stanford Univ.

Jackson, M., \& Colmer, T. (2005). Response and adaptation by plants to flooding stress. Annals of Botany, 96, 501-505.

James, L.A., Watson, D.G., \& Hansen, W.F. (2006). Using LiDAR data to map gullies and headwater streams under forest canopy: South Carolina, USA. Catena, 71, $132-144$

Japan Aerospace Exploration Agency (2013). Advanced land observing satellite-2 "DAICHI-2" (ALOS-2). Available at: http://global.jaxa.jp/projects/sat/alos2/topics. html\#topics 3394 (Accessed: 7 November 2014).

Jia, L., Xi, G., Liu, S., Huang, C., Yan, Y., \& Liu, G. (2009). Regional estimation of daily to annual regional evapotranspiration with MODIS data in the Yellow River Delta wetland. Hydrology and Earth System Sciences, 13, 1775-1787. 
Jones, K.L., Poole, G.C., O'Daniel, S.J., Mertes, L.A., \& Stanford, J.A. (2008). Surface hydrology of low-relief landscapes: Assessing surface water flow impedance using LIDAR-derived digital elevation models. Remote Sensing of Environment, 112, 4148-4158.

Kandus, P., Karszenbaum, H., Pultz, T., Parmuchi, G., \& Bava, J. (2001). Influence of flood conditions and vegetation status on the radar backscatter of wetland ecosystems. Canadian Journal of Remote Sensing, 27, 651-662.

Kasischke, E.S., Smith, K.B., Bourgeau-Chavez, L.L., Romanowicz, E.A., Brunzell, S., \& Richardson, C.J. (2003). Effects of seasonal hydrologic patterns in south Florida wetlands on radar backscatter measured from ERS-2 SAR imagery. Remote Sensing of Environment, $88,423-441$.

Kiage, L.M., Walker, N.D., Balasubramanian, S., Babin, A., \& Barras, J. (2005). Applications of Radarsat-1 synthetic aperture radar imagery to assess hurricane-related flooding of coastal Louisiana. International Journal of Remote Sensing, 26(24), 5359-5380.

Kim, J. -W., Lu, Z., Jones, J.W., Shum, C., Lee, H., \& Jia, Y. (2014). Monitoring Everglades freshwater marsh water level using L-band synthetic aperture radar backscatter. Remote Sensing of Environment, 150, 66-81.

Kim, J. -W., Lu, Z., Lee, H., Shum, C., Swarzenski, C.M., Doyle, T.W., \& Baek, S.H. (2009). Integrated analysis of PALSAR/Radarsat-1 InSAR and ENVISAT altimeter data for mapping of absolute water level changes in Louisiana wetlands. Remote Sensing of Environment, 113(11), 2356-2365.

Kim, S. -W., Wdowinski, S., Amelung, F., Dixon, T.H., \& Won, J. -S. (2013). Interferometric coherence analysis of the Everglades wetlands, South Florida. IEEE Transactions on Geoscience and Remote Sensing, 51, 5210-5224.

Kuenzer, C., Guo, H., Huth, J., Leinenkugel, P., Li, X., \& Dech, S. (2013). Flood mapping and flood dynamics of the Mekong Delta: ENVISAT-ASAR-WSM based time series analyses. Remote Sensing, 5, 687-715.

Kuenzer, C., Ottinger, M., Liu, G., Sun, B., Baumhauer, R., \& Dech, S. (2014a). Earth observation-based coastal zone monitoring of the Yellow River Delta: Dynamics in China's second largest oil producing region observed over four decades. Applied Geography, 55, 92-107.

Kuenzer, C., van Beijma, S., Gessner, U., \& Dech, S. (2014b). Land surface dynamics and environmental challenges of the Niger Delta, Africa: Earth observation based analyses spanning three decades (1986e2013). Applied Geography, 53, 354-368.

Laitinen, J., Rehell, S., \& Oksanen, J. (2008). Community and species responses to water level fluctuations with reference to soil layers in different habitats of mid-boreal mire complexes. Plant Ecology, 194, 17-36.

Lauknes, T. R., Zebker, H. A., \& Larsen, Y. (2011). InSAR Deformation Time Series Using anNorm Small-Baseline Approach. IEEE Transactions on Geoscience and Remote Sensing, 49, 536-546.

Li, S. -N., Wang, G. -X., Deng, W., Hu,, Y. -M., \& Hu, W. -W. (2009). Influence of hydrology process on wetland landscape pattern: A case study in the Yellow River Delta. Ecological Engineering, 35, 1719-1726.

Liu, Y., \& Huang, H. -J. (2013). Characterization and mechanism of regional land subsidence in the Yellow River Delta, China. Natural Hazards, 68, 687-709.

Lu, Z., Crane, M., Kwoun, O.I., Wells, C., Swarzenski, C., \& Rykhus, R. (2005). C-band radar observes water level change in swamp forests. Eos, 86, 141-144.

Lu, Z., \& Kwoun, O. -I. (2008). Radarsat-1 and ERS InSAR analysis over southeastern coastal Louisiana: Implications for mapping water-level changes beneath swamp forests. IEEE Transactions on Geoscience and Remote Sensing, 46, 2167-2184.

Mitsch, W.J. (1995). Restoration of our lakes and rivers with wetlands-An important application of ecological engineering. Water Science and Technology, 31, 167-177.

Parizzi, A., \& Brcic, R. (2011). Adaptive InSAR stack multilooking exploiting amplitude statistics: A comparison between different techniques and practical results. IEEE Geoscience and Remote Sensing Letters, 8(3), 441-445.

Patel, P., Hari, S.S., \& Ranganath, R.N. (2009). Use of synthetic aperture radar polarimetry to characterize wetland targets of Keoladeo National Park, Bharatpur, India. Current Science, 97(4), 529-537.

Perissin, D., \& Wang, T. (2012). Repeat-pass SAR interferometry with partially coherent targets. IEEE Transactions on Geoscience and Remote Sensing, 50, 271-280.

Pettitt, A.N. (1976). A two-sample Anderson-Darling rank statistic. Biometrika, 63(1), 161-168.
Poncos, V., Teleaga, D., Bondar, C., \& Oaie, G. (2013). A new insight on the water level dynamics of the Danube Delta using a high spatial density of SAR measurements. Journal of Hydrology, 482, 79-91.

Refice, A., Bovenga, F., \& Nutricato, R. (2006). MST-based stepwise connection strategies for multipass radar data, with application to coregistration and equalization. IEEE Transactions on Geoscience and Remote Sensing, 44, 2029-2040.

Rodriguez, G.F., Adam, N., Parizzi, A., \& Brcic, R. (2013). The Integrated Wide Area Processor (IWAP): A processor for wide area persistent scatterer interferometry. Proceedings of ESA Living Planet Symposium 2013. Edinburgh, UK: ESA Living Planet Symposium 2013 (9-13 September 2013).

Rodriguez Gonzalez, F., Bhutani, A., \& Adam, N. (2011). L1 network inversion for robust outlier rejection in persistent scatterer interferometry, Processing of IEEE International Conference on Geoscience and Remote Sensing Symposium, IGARSS 2011, Vancouver, Canada (pp, 75-78) (24-29 July 2011).

Samsonov, S. (2010). Topographic correction for ALOS PALSAR interferometry. IEEE Transactions on Geoscience and Remote Sensing, 48, 3020-3027.

Seabloom, E. W., van der Valk, A. G., \& Moloney, K. A. (1998). The role of water depth and soil temperature in determining initial composition of prairie wetland coenoclines. Plant ecology, 138, 203-216.

Scholz, F.W., \& Stephens, M.A. (1987). K-sample Anderson-Darling tests. Journal of the American Statistical Association, 82, 918-924.

Schutz, B., Zwally, H., Shuman, C., Hancock, D., \& DiMarzio, J. (2005). Overview of the ICESat mission. Geophysical Research Letters, 32, L21S01http://dx.doi.org/10.1029/ 2005GL024009.

Systems, Dataflow (2013). Odyssey Capacitive Water Level Logger. Available at: http:// odysseydatarecording.com/index.php? route =information/information\&information $\mathrm{id}=9$ (Accessed: 7 November 2014)

Taramelli, A., Giardino, C., Gasperini, L., del Bianco, F., Bresciani, M., Valentini, E., Pizzimenti, L., Zucca, F., \& Disperati, L. (2010). Biophysical and morphological study of coastal habitats from imaging spectrometry. LiDAR and in situ data acquisition. Frascati: The Hyperspectral Workshop 2010, ESRIN (17-19, March, 2010).

Taramelli, A., Valentini, E., Cornacchia, L., Mandrone, S., Monbaliu, J., Hoggart, S., Thompson, R.C., \& Zanuttigh, B. (2014). Modeling uncertainty in estuarine system by means of combined approach of optical and radar remote sensing. Coastal Engineering, $87,77-96$.

Turner, R.K. Van Den Bergh, J.C, Söderqvist, T, Barendregt, A van der Straaten, J. Maltby, E., \& van Ierland, E.C. (2000). Ecological-economic analysis of wetlands: Scientific integration for management and policy. Ecological Economics, 35, 7-23.

Wang, Y.. Hess, L.L., Filoso, S., \& Melack, J.M. (1995). Understanding the radar backscattering from flooded and nonflooded Amazonian forests: Results from canopy backscatter modeling. Remote Sensing of Environment, 54(3), 324-332.

Wdowinski, S., Amelung, F., Miralles-Wilhelm, F., Dixon, T.H., \& Carande, R. (2004). Spacebased measurements of sheet-flow characteristics in the Everglades wetland, Florida. Geophysical Research Letters, 31, L15503http://dx.doi.org/10.1029/2004GL020383.

Wdowinski, S., Kim, S. -W., Amelung, F., Dixon, T.H., Miralles-Wilhelm, F., \& Sonenshein, R. (2008). Space-based detection of wetlands' surface water level changes from L-band SAR interferometry. Remote Sensing of Environment, 112, 681-696.

Werner, C., Wegmüller, U., Strozzi, T., Wiesmann, A., \& Santoro, M. (2007). PALSAR multimode interferometric processing. Proceedings of the First Joint PI Symposium of ALOS Data Nodes for ALOS Science Program, Kyoto, Japan (pp. 19-23) (19-23 November 2007).

Xie, C., Shao, Y., Xu, J., Wan, Z., \& Fang, L. (2013). Analysis of ALOS PALSAR InSAR data for mapping water level changes in Yellow River Delta wetlands. International Journal of Remote Sensing, 34, 2047-2056.

Xue, C. (1993). Historical changes in the Yellow River delta, China. Marine Geology, 113, 321-330.

Yue, T.X., Liu, J.Y., Jørgensen, S.E., \& Ye, Q.H. (2003). Landscape change detection of the newly created wetland in Yellow River Delta. Ecological Modelling, 164, 21-31. 